\title{
The signaling pathway mediated by the type IIB activin receptor controls axial patterning and lateral asymmetry in the mouse
}

\author{
Suk P. Oh and $\mathrm{En} \mathrm{Li}{ }^{1}$ \\ Cardiovascular Research Center, Massachusetts General Hospital-East and Department of Medicine, Harvard Medical \\ School, Charlestown, Massachusetts 02129 USA
}

\begin{abstract}
Vertebrate animals exhibit segmented axial skeletons and lateral asymmetry of the visceral organs. The segment identity of individual vertebrae is believed to be determined by a combination of functionally active Hox genes that have defined expression boundaries along the anteroposterior axis (known as the axial Hox code). Disturbance of the Hox code by ectopic expression or mutation of Hox genes often leads to homeotic transformation of the vertebrae. Largely unknown, however, are the signaling molecules that provide the positional cues for the precise establishment and maintenance of the Hox code. In this study we show that disruption of the type IIB activin receptor (ActRIIB) by gene targeting results in altered expression of multiple Hox genes and abnormal patterning of the vertebrae, similar to but severer than retinoic acid (RA)-induced anterior transformation. We further show that RA and ActRIIB mutation have synergistic effects on vertebral patterning. Activin, $\mathrm{Vg}-1$ and, type II activin receptors have been implicated in regulation of lateral asymmetry during chick and Xenopus development. We show here that the ActRIIB ${ }^{-1-}$ mice die after birth with complicated cardiac defects including randomized heart position, malposition of the great arteries, and ventricular and atrial septal defects. In addition, the heart anomalies are associated with right pulmonary isomerism and splenic abnormalities, recapitulating the clinical symptoms of the human asplenia syndrome. These findings provide genetic evidence that the ActRIIB-mediated signaling pathway plays a critical role in patterning both anteroposterior and left-right axes in vertebrate animals.
\end{abstract}

[Key Words: Activin/BMP; serine/threonine kinase receptor; axial skeleton; lateral asymmetry; asplenia syndrome]

Received April 11, 1997; revised version accepted May 30, 1997.

Activins are members of the transforming growth factor- $\beta$ (TGF- $\beta$ ) superfamily that exert a diverse range of biological effects on cell growth and differentiation (for review, see Mathews 1994). Activins signal through interactions with their cell surface serine/threonine kinase receptors. Two type II receptors, ActRIIA and ActRIIB, have been identified as activin receptors based on their high-affinity binding to activins (Mathews and Vale 1991; Attisano et al. 1992). Several type I TGF- $\beta$ family receptors have been cloned, among which the ActRIA (ALK-2) and ActRIB (ALK-4) have been shown to bind to activins in the presence of the type II activin receptors (Attisano et al. 1993; ten Dijke et al. 1994). Although both type I and type II receptors are required for signaling, the type II receptors function primarily as the binding receptors that, upon binding to the ligands, associate with and phosphorylate the type I receptors that, in turn, activate the downstream signaling path-

${ }^{1}$ Corresponding author.

E-MAIL en@cvrc.mgh.harvard.edu; FAX (617) 726-5806. ways (Wrana et al. 1994; Attisano et al. 1996). Recently, the Smad family proteins have been shown to act downstream of the type I receptor and probably function as transcription regulatory factors (Chen et al. 1996; Liu et al. 1996; for review, see Derynck and Zhang 1996; Massagué 1996). Although ligand binding analysis has assigned both ActRIIA and ActRIIB as activin receptors, the evidence for their interactions during development has yet to be established.

Several functional tests have indicated that the ActRIIB may play an important role in axial patterning during vertebrate development. In Xenopus, over-expression of a truncated ActRIIB receptor (tXAR), in which the serine/threonine kinase domain is deleted, blocks activin signaling in mesoderm induction (HemmatiBrivanlou and Melton 1992). Interestingly, over-expression of the tXAR can also inhibit mesoderm induction by $\mathrm{Vg} \cdot 1$, another highly potent mesoderm-inducing factor of the TGF- $\beta$ family, suggesting that ActRIIB may mediate Vg-1 signaling as well (Schulte-Merker et al. 1994). Activin, Vg-1, and the type II activin receptors have also 
been implicated in determination of left-right asymmetry (or laterality) in vertebrates (Levin et al. 1995; Hyatt et al. 1996). Injection of Vg-1 mRNA into the right-dorsal blastomere of 16-cell-stage Xenopus embryos resulted in randomized heart position. Furthermore, injection of the truncated receptor tXAR to the left-dorsal blastomere of the same stage embryos also caused randomized heart situs (Hyatt et al. 1996). In the chick, ActRIIA expression is restricted to the right side of Hensen's node, whereas ActRIIB is expressed symmetrically around the node. When ActRIIA was ectopically induced on the left side of the node by applying recombinant activin to the left, the heart situs became randomized (Levin et al. 1995). The gene knock-out experiments in mice, however, have shown that the zygotic activins A and B and the ActRIIA receptor are not required for the formation of mesoderm and left-right asymmetry (Matzuk et al. 1995a,b), raising the possibility that other TGF- $\beta$ family ligands or the ActRIIB receptor might be involved in these processes.

ActRIIB is expressed in the epiblast (the primitive ectoderm) of pregastrulation mouse embryos and in the embryonic ectoderm throughout gastrulation (Manova et al. 1995), consistent with the possibility that ActRIIB transduces the signal of activin or an activin-like molecule in mesoderm induction and early morphogenesis. During organ development in mid-gestation embryos, ActRIIB is expressed in various tissues such as the brain, spinal cord, limb, metanephros, stomach, and intestine (Feijen et al. 1994; Manova et al. 1995). The widespread expression of the ActRIIB suggests that it may play an important role in the development and morphogenesis of various organs. In this study we show that disruption of the ActRIIB gene leads to complicated cardiac defects, disturbance of lateral asymmetry, and homeotic transformation of the axial skeleton. Our observations indicate that the ActRIIB-mediated signaling pathway plays a key regulatory role in patterning the anteroposterior and left-right body axes.

\section{Results}

Targeted disruption of the ActRIIB gene results in postnatal lethality

To understand the role of ActRIIB in mouse development, we disrupted the ActRIIB gene by homologous recombination in embryonic stem (ES) cells. The deleted genomic fragment of the ActRIIB gene in the targeting vector contains the exons coding for the entire transmembrane domain and the amino-terminal region of the kinase domain, which are essential for the receptor function (Fig. 1A). This fragment also contains all of the necessary sequences for the generation of the four splicing variants (Attisano et al. 1992). It was predicted, therefore, that the mutation would result in complete inactivation of all four isoforms. Because the transmembrane domain was deleted, it was also predicted that the mutant gene product, if produced, would be unlikely to have dominant-negative effects.

Mice heterozygous for the disrupted ActRIIB gene were generated and appeared grossly normal. The heterozygous mice were intercrossed, and the genotype of the progenies were determined by Southern blot or PCR analysis (Fig. 1B,C). Of 241 offspring on the $129 / \mathrm{Sv}$ inbred background, no viable homozygous mutant mice $\left(\right.$ ActRIIB $\left.^{-1-}\right)$ were found at the weaning age, indicating that ActRIIB mutation was recessive lethal (Table 1). However, on the $129 / \mathrm{Sv}-\mathrm{C} 57 \mathrm{BL} / 6$ hybrid background, $\sim 30 \%$ of the homozygotes were viable and fertile (Table 1). To determine whether the ActRIIB ${ }^{-1-}$ fetuses die in utero or after birth, homozygous male mice (hybrid) were mated with heterozygous female mice, and fetuses were examined at 18.5 days postcoitum (E18.5). Of 143 fetuses from 18 pregnant mice, $73(51 \%)$ homozygotes were all alive with normal external appearance (Table 1). Examination of a large number of embryos in the $129 / \mathrm{Sv}$ inbred strain did not reveal gross morphological abnormality in ActRIIB $^{-/-}$embryos. Although ActRIIB ${ }^{-/-}$embryos developed to term, dead pups were recovered in a few days after birth, the majority of which were found to be homozygotes, indicating that ActRIIB deficiency resulted in postnatal lethality. To investigate the cause of lethality of the ActRIIB ${ }^{-/-}$mice, we examined newborn mice born naturally or by cesarean section. We found that the ActRIIB $^{-/-}$pups frequently showed cyanosis (Fig. 1D) and died later, indicative of possible cardiovascular defects. Autopsies performed on the ActRIIB ${ }^{-1-}$ mice revealed a number of defects in the heart and other visceral organs.

\section{ActRIIB deficiency leads to complicated cardiac defects}

The hearts of the ActRIIB ${ }^{-/-}$mice showed various patterning defects. In normal mice the heart is located on the left side of the chest and the apex points to the left. The venous blood enters the right atrium from the superior and inferior vena cavae, then flows to the lungs from the right ventricle (RV) via the pulmonary artery (PA). Oxygenated blood returns to the left atrium and flows to the whole body via the aorta (Ao) from the left ventricle (LV). To highlight the arteries and examine the blood flow through the arteries, we injected yellow casting dye directly into the RV followed by blue dye to the LV. In a normal heart, dyes were not mixed as indicated by the presence of the yellow dye in the pulmonary trunk (PT) and the blue dye in the Ao. The PT is located anterior to and to the right of the Ao and crosses over to the left of the Ao (Fig. 2A). In the mutant hearts, however, the dyes were mixed extensively, indicating ventricular and/or atrial septal defects, and the two great arteries were located in abnormal positions. The Ao in the ActRIIB ${ }^{-1-}$ mice arose from the anterior-most position of the heart, where the PT was located in the wild type, whereas the PT was located posterior to, and on either the left or the right side of, the Ao, and the PT and the Ao were in parallel positions without crossing over each other (Fig. 2B-F). These abnormalities of the outflow tract are similar to the human congenital heart defects known as transposition of the great arteries (TGA) 

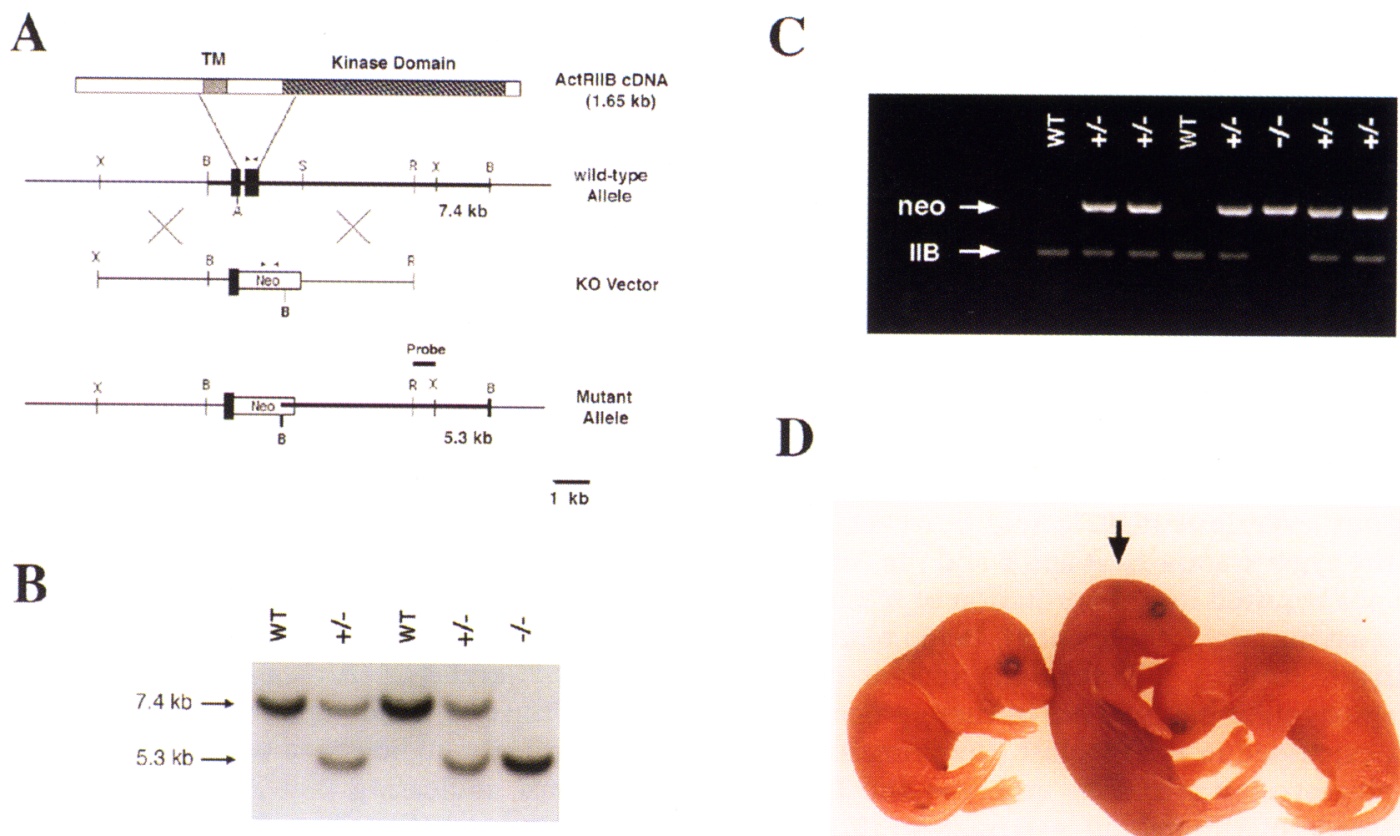

\section{D}

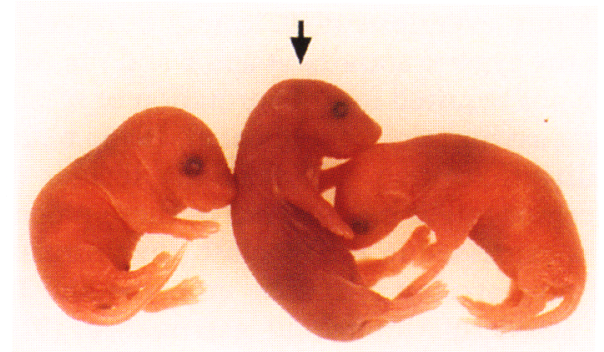

Figure 1. Targeted disruption of the ActRIIB gene. $|A|$ Schematic diagrams (from top to bottom) of the ActRIIB cDNA, the wild-type gene locus, the targeting vector, and the mutant allele after homologous recombination. The ActRIIB coding sequences can be divided into three functional domains including the ligand binding, transmembrane (TM), and Ser/Thr kinase domains. A 1.7-kb ApaI-SmaI genomic fragment containing exons (filled rectangles) that encode 123 amino acid residues comprising the entire transmembrane domain was deleted and replaced with a PGK-neomycin resistant cassette. A BamHI site is introduced into the targeted ActRIIB locus from the neomycin cassette, and the 7.4-kb and 5.3-kb BamHI fragments from the wild-type and the mutant alleles, respectively, are shown as thicker lines. A 3' external probe (R-X fragment) for Southern hybridization and the PCR primers (arrowheads) are indicated. Restriction enzymes: (A) ApaI; (B) BamHI; (R) EcoRI; (S) SmaI; (X) XbaI. (B) Southern blot analysis of tail DNA from offspring generated by intercrosses of $A c t R I I B^{+/-}$heterozygotes. DNA was digested with BamHI, blotted, and hybridized to the probe indicated, and a $5.3-\mathrm{kb}$ band from the mutant allele and a $7.4-\mathrm{kb}$ band from the wild-type allele were detected. $(C)$ PCR analysis of genotype. Two sets of primers were used for genotyping. One set is from the neomycin cassette, and the other is from the ActRIIB exon that is deleted in the KO vector. The absence of the ActRIIB-specific band indicates the complete deletion of the transmembrane domain in ActRIIB ${ }^{-/-}$ offspring. (D) A newborn $A c t R I I B^{-/-}$mouse (center) with two normal littermates. Note the darker skin color caused by cyanosis.

or double outlet right ventricle (DORV). It is noteworthy that the septation between the Ao and the PT was well formed in almost all of the ActRIIB ${ }^{-/-}$mutants (Fig. 2B$\mathrm{F}$ ), suggesting that the cardiac defect was not persistent truncus arteriosus (PTA). The ductus arteriosus of the mutant heart was obstructed as in the wild-type heart. One hundred percent (37 out of 37) of ActRIIB $^{-1-}$ mice on the $129 / \mathrm{Sv}$ background and $-60 \%$ (31 out of 50 ) on the hybrid background showed defects in the patterning of the outflow tract.

In addition, the ActRIIB ${ }^{-/-}$mice on $129 / \mathrm{Sv}$ back-

Table 1. Genotype analysis of viable offspring at weaning age or E18.5 fetuses

\begin{tabular}{|c|c|c|c|c|c|c|}
\hline & \multirow[b]{2}{*}{ Cross } & \multirow[b]{2}{*}{ Strain } & \multirow{2}{*}{$\begin{array}{c}\text { Total } \\
\text { progeny }\end{array}$} & \multicolumn{3}{|c|}{ Genotype } \\
\hline & & & & $+1+$ & $+1-$ & $-1-$ \\
\hline \multirow{3}{*}{ Adult } & $(+1-1 \times(+1-1$ & $129 / \mathrm{Sv}$ & 241 & 83 & 158 & 0 \\
\hline & $(+1-) \times(+1-1$ & hybrid & 155 & 56 & 91 & 8 \\
\hline & $(-1-) \times(+1-1$ & hybrid & 253 & 一 & 196 & 57 \\
\hline E18.5 & $(-1-) \times 1+1-1$ & hybrid & 143 & - & 70 & 73 \\
\hline
\end{tabular}

ground showed abnormal positioning of the heart within the chest and abnormal looping of the descending Ao. The position of the mutant heart was randomized, and the apex pointed in a random direction instead of to the left as in the normal mice. In $\sim 30 \%$ of the mutant mice (11 out of 37 ), the apex pointed toward the right (dextrocardia; Fig. 2B,C), $40 \%$ (15 out of 37 ) to the left (levocardia; Fig. 2D,E), and the rest $30 \%$ (11 out of 37$)$ to the middle (mesocardia). Independent of the position of the heart, the descending Ao looped either toward the left side $(49 \%, 18$ out of 37 ; Fig. 2 B,C) or the right side $(51 \%$, 19 out of 37; Fig. 2D-F), instead of looping to the left as in the wild-type mice (Fig. 2A). On the hybrid background, the frequency of dextrocardia was lower.

To discern the heart defects at the histological level, serial frontal sections were examined after hematoxylin and eosin staining. Histological analysis confirmed the abnormal patterning of the outflow tract and ventricular and atrial septal defects in the ActRIIB ${ }^{-/-}$mice. In the wild-type heart, the PT appeared first (Fig. 3A) and was connected to the RV, followed by the Ao to the LV (Fig. $3 \mathrm{Cl}$. The atrial and ventricular septa were completely formed. In the mutant heart (Fig. 3E-L), however, Ao was 

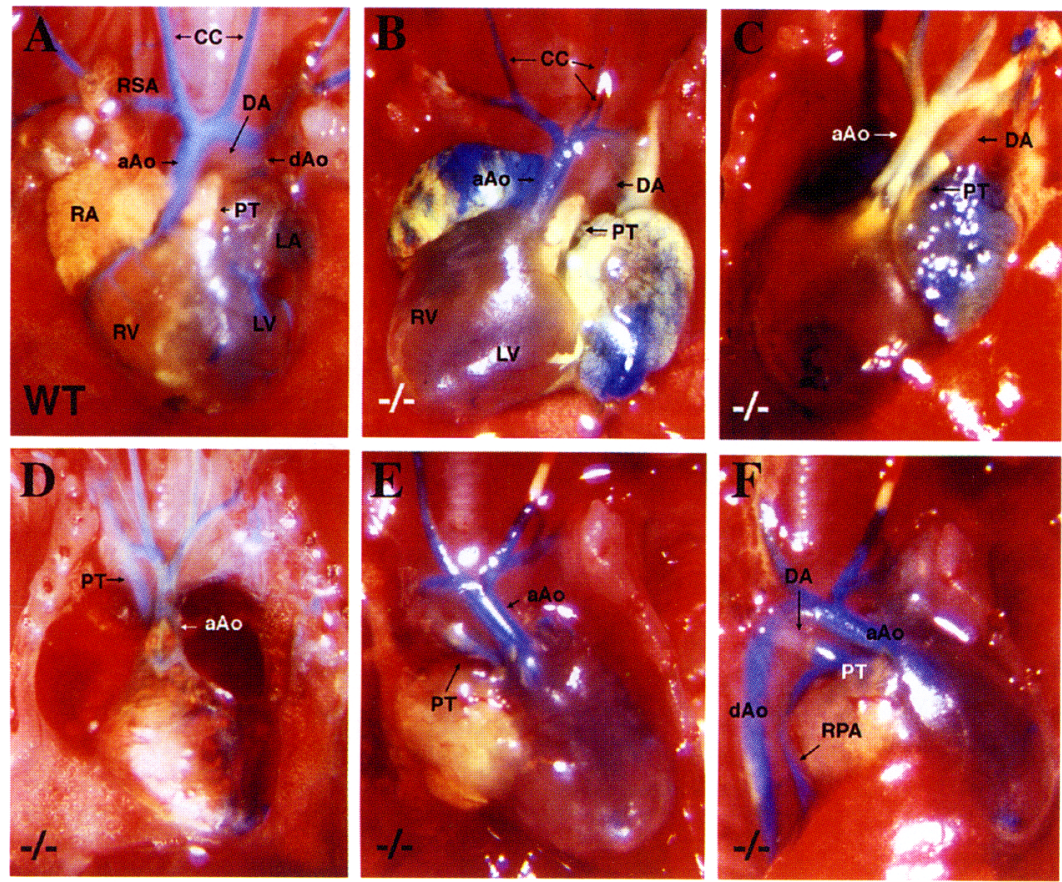

Figure 2. Cardiac anomalies in $A c t R I I B^{-/-}$ newborn mice. The hearts of a wild-type $(A)$ and four ActRIIB ${ }^{-1-}(B-F)$ newborn mice are labeled with dyes by injection of yellow dye first into the RV followed by the blue dye into the LV. In the wild-type heart $\langle A\rangle$, the PT contains yellow dye, whereas the ascending aorta $(\mathrm{aAo})$ contains blue dye, without the mixing of the two dyes in any part of the heart. In the mutant heart, the mixing of the two dyes is seen in the atria $(B)$, in the aAo $|C-E|$, and in the PT $|C, D|$, indicating ventricular and/or atrial septal defects. The ductus arteriosus (DA) is closed in the mutant heart as indicated by the absence of dye. $(B, C)$ Two mutant mice show dextrocardia with apexes pointing to the right. The PT is located to the left of the aAo, and the descending aorta (dAo) loops to the left side. Note the split common carotid arteries $(C C)$ in $B .(D, E)$ Mutant mice with levocardia in which the PT is located to the right of the aAo, and the dAo loops to the right side. $(F)$ Side view of $E$ showing a closed ductus arteriosus and the rightward looping of the dAo. Other abbreviations: (LA) left atrium; (RA) right atrium; (RPA) right pulmonary artery; (RSA) right subclavian artery.
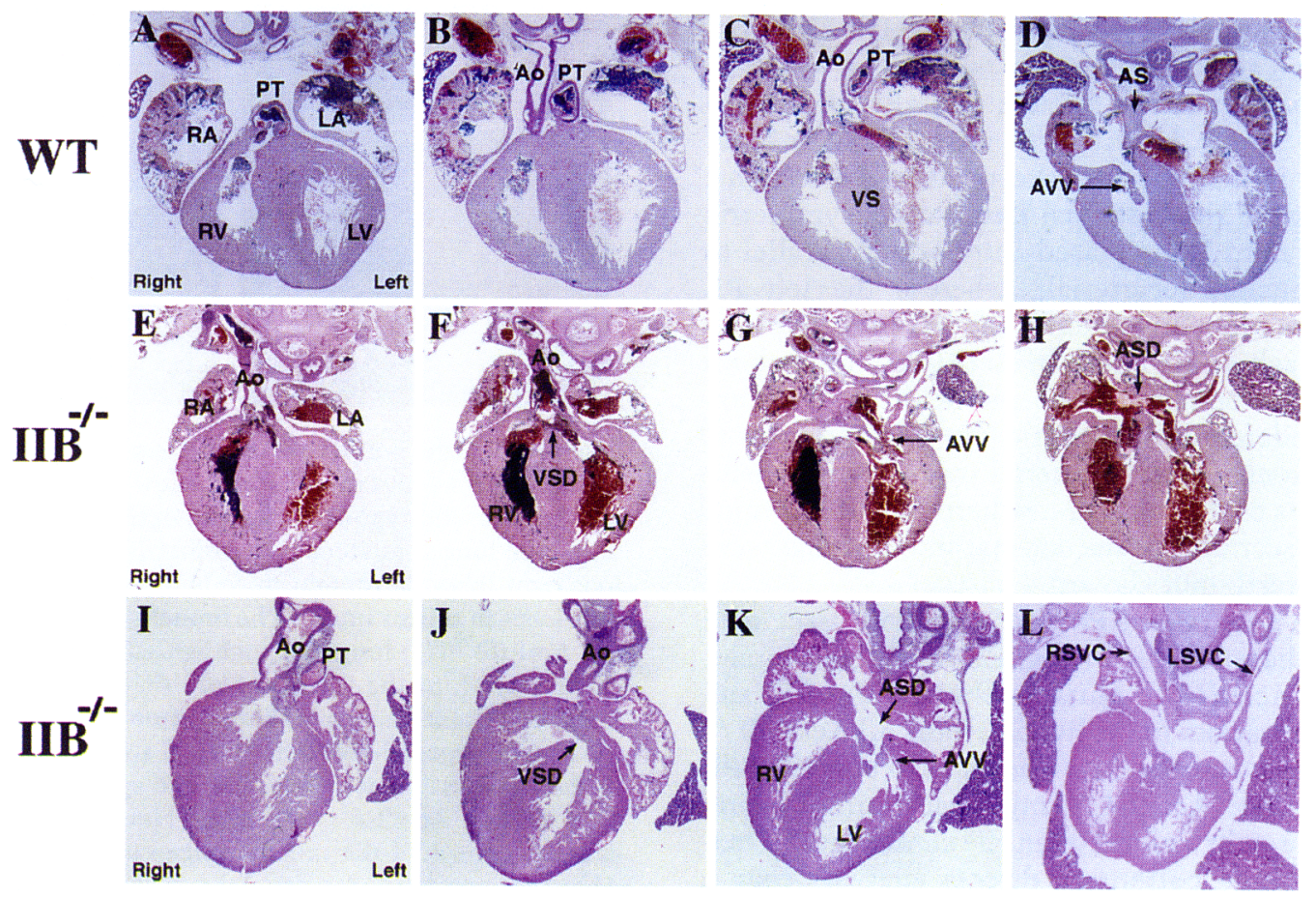

Figure 3. Frontal sections of the heart of wild-type and ActRIIB ${ }^{-/-}$newborn mice. Four serial sections from ventral to dorsal side of a wild-type heart $(A-D)$ and two ActRIIB ${ }^{-/-}$-mutant hearts $[(E-H)$ mesocardia $;(I-L)$ dextrocardia]. In the wild-type heart, the PT arises from the RV $(A)$, and the Ao from the LV $(C)$. Ventricles and atria are completely septated throughout the series. In ActRIIB ${ }^{-/-}$-mutant hearts, the Ao is at the position where the PT is normally placed in the wild type (cf. $E$ and $I$ with $A$ ). Both the RV and LV are connected to the Ao owing to a high ventricular septal defect (VSD) (F,J). The RA and LA are also connected owing to an atrial septal defect (ASD) $(H, K)$. The LSVC is connected to the left atrium, indicating an atrial isomerism $(L)$. Abbreviations: (AS) atrial septum; (AVV) atrioventricular valve; (LSVC) left superior vena cava; (RSVC) right superior vena cava; (VS) ventricular septum; and see Fig. 2. 
at the most anterior position (Fig. 3E,I) and was connected to both the RV and LV owing to the defective ventricular septum right underneath the Ao (Fig. 3F,I). Atrial septal defects were also apparent in the mutant hearts (Fig. $3 \mathrm{H}, \mathrm{K}$ ). In normal mice both left and right superior vena cavae are connected to the right atrium of the heart (not shown), whereas in many mutant mice the left superior vena cava was connected to the left atrium (Fig. 3L). The gross morphology of the ventricles of the mutant heart was normal.

\section{ActRIIB deficiency results in right isomerism}

Because the congenital heart defects such as dextrocardia and TGA are often associated with laterality defects in human (Van Praagh et al. 1992; Perloff 1994; Phoon and Neill 1994), we examined other organs in ActRIIB ${ }^{-1-}$ mice, which were also abnormal in human patients with laterality defects. We found that the ActRIIB ${ }^{-/-}$mice exhibited right pulmonary isomerism, bilateral right atrial appendages, and splenic abnormalities, resembling the clinical symptoms of the asplenia syndrome for right isomerism) in human.

In wild-type mice, the right lung has four lobes including cranial, medial, caudal, and accessory lobes, whereas the left lung has one (Fig. 4A,C). This asymmetric pattern of lung lobation was, however, altered in the Ac$\mathrm{tRIIB}^{-/-}$mice in which the left lung also had four lobes, in mirror image to the right lung (Fig. 4B,D). This condition is known as right pulmonary isomerism (RPI). The asymmetric pattern of the bronchi was also affected in the ActRIIB ${ }^{-1-}$ mice. In wild-type mice the right bronchus is larger in diameter but shorter than the left one, and the pattern of the bronchial tree is also asymmetric (Fig. 4E). The right PA is placed anterior and parallel to the right bronchus (eparterial), whereas the left PA crosses the left bronchus to enter the left lung (hyparterial) (Van Praagh et al. 1992). In ActRIIB-/- mice, both morphology and branching patterns of the bronchi appeared to be bilaterally symmetric (Fig. 4F), and in most cases, both bronchi were eparterial (not shown). Histological analysis of the lungs of newborn ActRIIB $^{-/-}$mice revealed no discernible tissue defects, and the lungs were inflated after birth (not shown).

It should be noted that RPI was completely associated with the cardiac defects. In the $129 / \mathrm{Sv}$ inbred strain, $100 \%$ of the ActRIIB ${ }^{-/}$mutants showed the RPI and cardiac malformation. In the hybrid strain, all ActRIIB ${ }^{-/-}$ mice with heart outflow tract defects also showed RPI, whereas all viable ActRIIB $^{-/-}$mice had normal hearts and lungs. The tight link between the cardiac malformation and the lung patterning defects suggests that a single embryonic process might be disrupted by the ActRIIB mutation.

The morphological right and left atria can be distinguished by several morphological markers including shape of the appendage, width and shape of the junction in the sulcus terminalis, venous connections, and the extension of the pectinate muscles within the append-
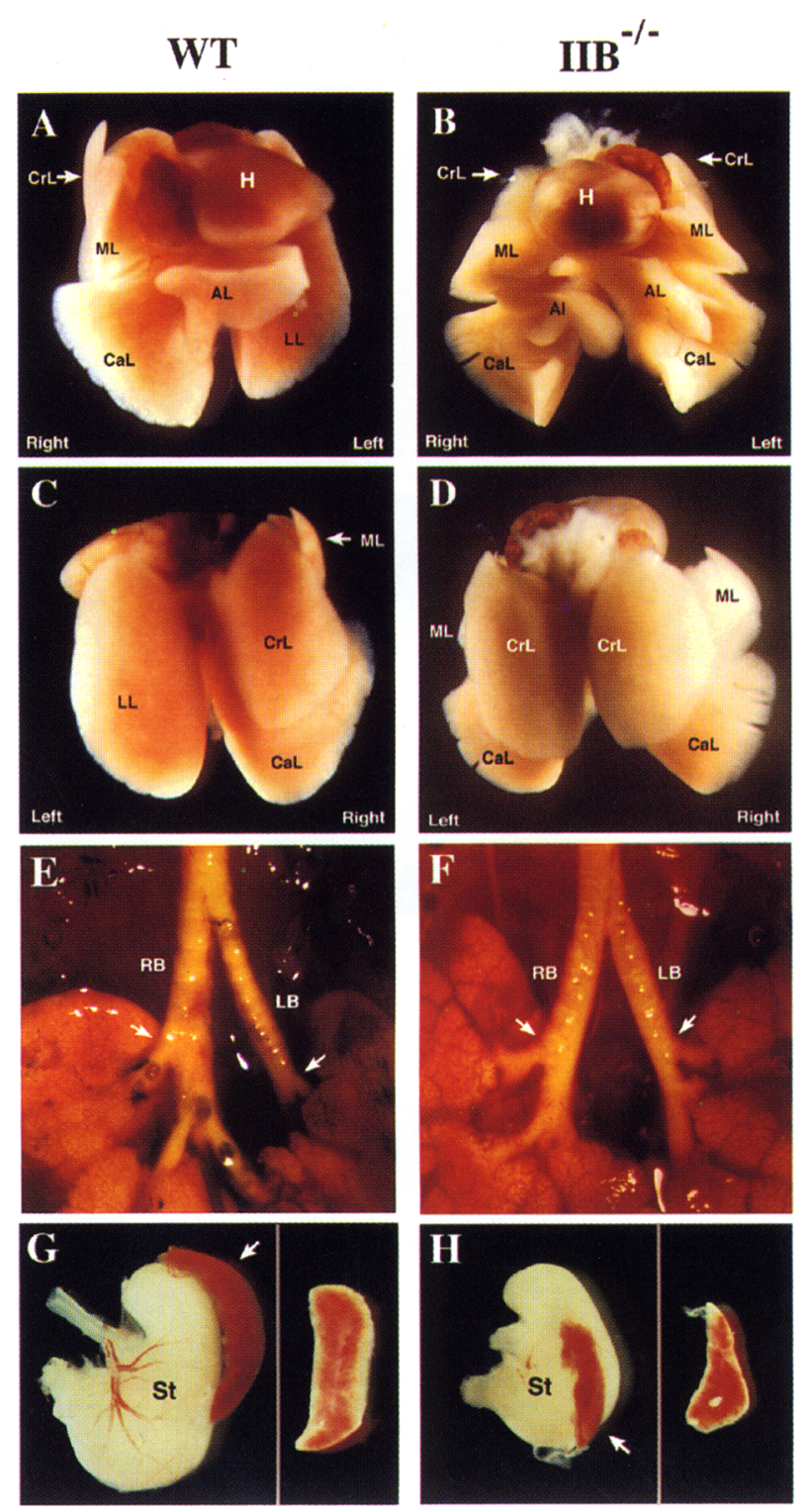

Figure 4. Right pulmonary isomerism and splenic defects in the $A c t R I I B^{-1-}$ mutants. Ventral view $(A, B)$ and dorsal view $(C, D)$ of the wild-type $(A, C)$ and the $A c t R I I B^{-/-}(B, D)$ lungs. The wild-type lung is bilaterally asymmetric with one left lobe and four right lobes. In mutant mice both left and right lungs have four lobes in mirror image. The bronchi of the wild-type $(E)$ and the ActRIIB ${ }^{-1-}(F)$ lungs are highlighted by injection of yellow casting dye into the trachea. Note that the right bronchus is larger and branches at a higher position than the left bronchus in the wild type, whereas the bronchi are bilaterally symmetric in the ActRIIB ${ }^{-1-}$ mice. Stomachs and spleens (arrows) in wildtype $\{G\}$ and $A c t R I I B^{-1-}(H)$ mice. Note the smaller size and abnormal shape of the mutant spleen (see the insets at right). Abbreviations: (AL) accessory lobe; $(\mathrm{CaL})$ caudal lobe; $(\mathrm{CrL})$ cranial lobe; $(\mathrm{H})$ heart; $(\mathrm{ML})$ medial lobe; (LB) left bronchus; (LL) left lung; (RB) right bronchus; (St) stomach.

ages (Seo et al. 1992; Anderson et al. 1996). We found, for example, that some mutant hearts showed that the left superior vena cava was connected to the left atrium (Fig. 
$3 \mathrm{~L}$ ), indicative of right atrial isomerism. Examination of the atria of the ActRIIB $^{-/-}$hearts in the $129 / \mathrm{Sv}$ strain using these criteria revealed that $\sim 30 \%$ of the mutant mice showed right atrial isomerism.

The abdominal visceral organs were also affected in the ActRIIB ${ }^{-/-}$mice. The spleens of the mutant mice were smaller and abnormally shaped as compared with the wild-type littermates (Fig. 4G,H). The mutant liver had the same number and patterns of lobes as the wild type, but the shape of some lobes was slightly altered (not shown). These phenotypes are probably related to the laterality defects such as agenesis or hypoplasia of spleens and transverse livers observed in the human asplenia syndrome. In addition, the ActRIIB homozygous mice also showed a spectrum of renal abnormalities, including uni- or bilateral agenesis, or hypoplasia in both the $129 / \mathrm{Sv}$ inbred strain (30 out of $34,88 \%$ ) and in the hybrid strain (54 out of $102,53 \%$ ). The kidney defects were not linked to the cardiac malformation and RPI. The stomach, gut, adrenal glands, urinary bladder, and male or female genital structures were present and normal in ActRIIB ${ }^{-/-}$mice (not shown).

\section{Abnormal patterning of the vertebrae and altered expression patterns of multiple Hox genes in ActRIIB $^{-1-}$ mice}

Examination of skeletons of newborn mice revealed abnormal patterning of the vertebrae in the ActRIIB ${ }^{-/-}$ mice. The vertebral column of wild-type mice consists of 7 cervical vertebrae $(\mathrm{C}), 13$ thoracic vertebrae $(\mathrm{T})$ characterized by the attachment of ribs, 6 lumbar vertebrae (L), 3 or 4 fused sacral vertebrae (S), and the caudal vertebrae (Fig. 5A). The ActRIIB ${ }^{-/-}$mice exhibited normal number and morphology of the cervical and lumbar vertebrae but had 16 thoracic vertebrae, 3 more than their wild-type or heterozygous littermates, thus displaying the C7/T16/L6 vertebral configuration (Fig. 5B; Table 2). The viable adult hybrid ActRIIB ${ }^{-1}$ mice also had the C7/T16/L6 vertebral pattern, indicating that the abnormal vertebral column did not affect the viability of the mouse.

In the wild-type mice, the first seven ribs attach to the sternum (vertebrosternal ribs) and the remaining six ribs (free ribs) end freely (Fig. 5A,C). The ActRIIB ${ }^{-1-}$ mice,

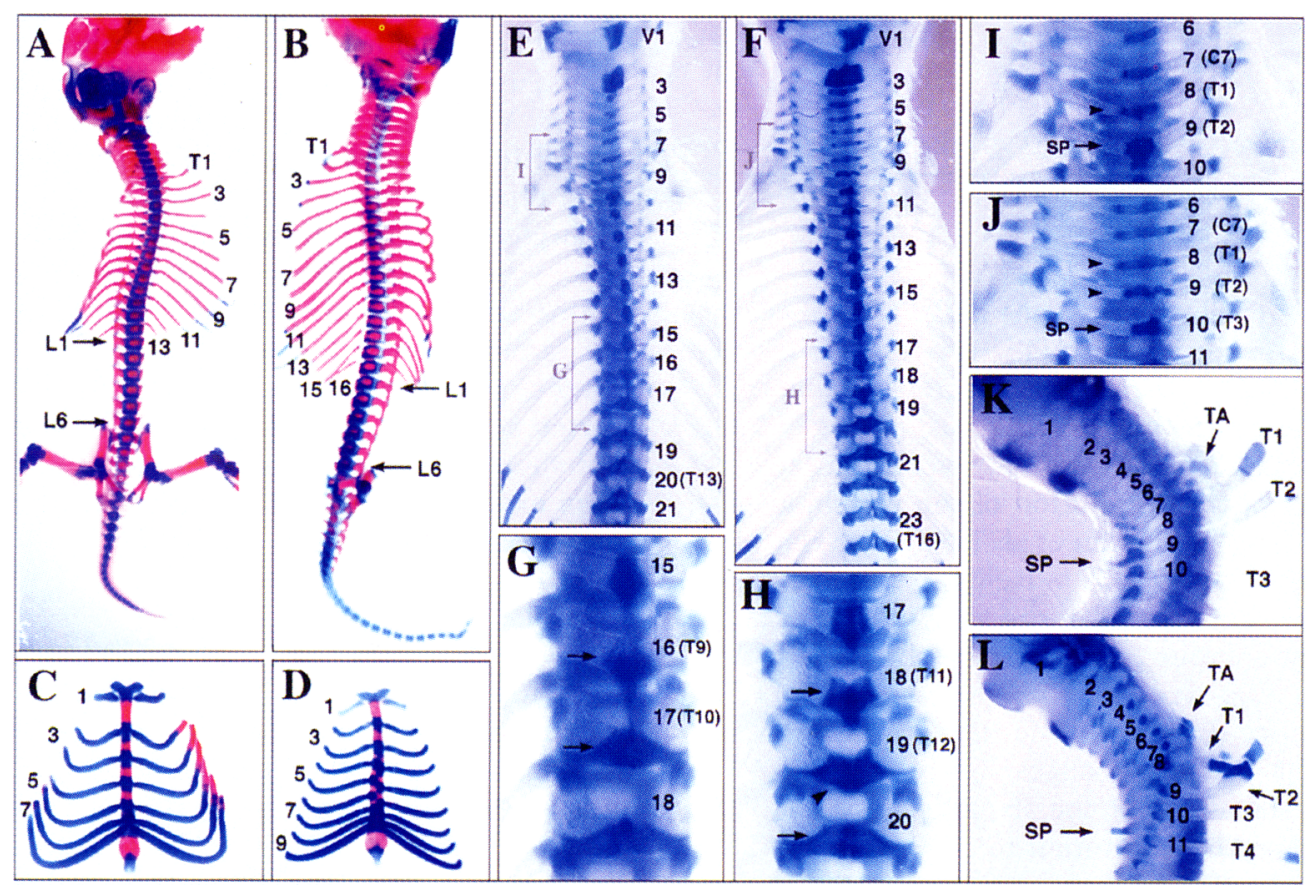

Figure 5. Abnormalities of the axial skeletons and ribs in $A c t R I I B^{-1-}$ mice. The skeleton of the E18.5 fetus was stained with alcian blue and alizarin red $S(A-D)$ or alcian blue alone $(E-L) .(A, B)$ Ventral view of the skeleton of wild-type $(A)$ and $A c t R I B^{-1-}(B)$, showing C7/T13/L6 and C7/T16/L6 vertebral patterns, respectively. Clavicula and forelimbs were removed, and the rib cage was cut open. Ribs attached to the thoracic vertebrae $(T)$, and the lumbar vertebrae $(L)$ are numbered. $(C, D)$ Vertebrosternal ribs of wild-type $(C)$ and ActRIIB $^{-1-}\left\{D \mid\right.$ mice. Note irregular shape of the sternebrae in the mutant mice. $(E, F)$ Dorsal view of the wild-type $(E)$ and ActRIIB ${ }^{-1-}$ $(F)$ vertebrae. The vertebrae are numbered from the first cervical vertebrae (Atlas). $(G, H)$ Magnified view of midthoracic vertebrae. The last vertebra showing caudally extending spinal process is V16 in the wild type $(G)$ but V18 in ActRIIB ${ }^{-/-}$mice $(H)$. The arrows indicate the transition of the shape of the spinal process in the vertebrae. The arrowhead indicate that the spinous process of V19 in mutant mice also points in the posterior direction although it has a similar disc shape as V17 in wild-type. (I,J) Magnified view of cervicothoracic vertebrae. The arrowheads indicate the similarity of the dorsal structures of V8 in the wild type $(I)$ to V8 and V9 in the ActRIIB $^{-1-}$ vertebrae $(J) .(K, L)$ Lateral view of the vertebrae. The tuberculi anterior (TA) is present at V6 in both wild-type $(K)$ and $\mathrm{ActRIIB}^{-/-}(L)$ vertebrae. The largest spinous process $(\mathrm{SP})$ is located at V9 in the wild type $(I, K)$ but at V10 in the mutant vertebrae $(J, L)$. Note the fusion of $\mathrm{T} 1$ and $\mathrm{T} 2$ ribs in the mutant vertebrae $(B, L)$. 
Table 2. Vertebral patterns of normal and mutant mice

\begin{tabular}{|c|c|c|c|c|c|}
\hline \multirow[b]{2}{*}{ Genotype } & \multicolumn{2}{|c|}{$-\mathrm{RA}$} & \multicolumn{3}{|c|}{$+\mathrm{RA}$} \\
\hline & $+1-$ & $-1-$ & $+1+$ & $+1-$ & $-1-$ \\
\hline \multicolumn{6}{|l|}{ Vertebral patterns } \\
\hline C7 T13 L5 & 1 & 0 & 0 & 0 & 0 \\
\hline L6 & 59 & 0 & 6 & 4 & 0 \\
\hline L7 & 0 & 0 & l & 1 & 0 \\
\hline T14 L5 & 4 & 0 & 0 & 1 & 0 \\
\hline L6 & 0 & 0 & 21 & 29 & 0 \\
\hline L7 & 0 & 0 & 0 & 3 & 0 \\
\hline T15 L6 & 0 & 0 & 0 & 1 & 0 \\
\hline T16 L5 & 0 & 3 & 0 & 0 & 0 \\
\hline L6 & 0 & 54 & 0 & 0 & 0 \\
\hline L7 & 0 & 1 & 0 & 0 & 0 \\
\hline T17 L5 & 0 & 2 & 0 & 0 & 0 \\
\hline L6 & 0 & 2 & 0 & 0 & 0 \\
\hline L7 & 0 & 0 & 0 & 0 & 1 \\
\hline T18 L0 & 0 & 0 & 0 & 0 & 2 \\
\hline L3 & 0 & 0 & 0 & 0 & 1 \\
\hline L5 & 0 & 0 & 0 & 0 & 3 \\
\hline L6 & 0 & 0 & 0 & 0 & 5 \\
\hline T19 L0 & 0 & 0 & 0 & 0 & 1 \\
\hline L5 & 0 & 0 & 0 & 0 & 2 \\
\hline \multicolumn{6}{|l|}{ Vertebrosternal ribs } \\
\hline 7 & 64 & 0 & 17 & 15 & 0 \\
\hline 8 & 0 & 5 & 11 & 24 & 0 \\
\hline 9 & 0 & 57 & 0 & 0 & 3 \\
\hline 10 & 0 & 0 & 0 & 0 & 12 \\
\hline Total no. of embryos & 64 & 62 & 28 & 39 & 15 \\
\hline
\end{tabular}

however, had 9 vertebrosternal ribs and 7 free ribs (Fig. $5 B, D$ ). Frequently, the first rib (T1) on vertebra 8 (V8) fused to the second rib (T2) on the ventral side and connected to the sternum at the T2 position (Fig. 5B,L). Similar phenotype has also been observed in other mutants with anterior transformation of the vertebrae (Alkema et al. 1995; Subramanian et al. 1995). The shape of the dorsal side of the V9 (T2) vertebra of mutant mice was similar to that of V8 (T1) of the wild-type mice (Fig. $5 \mathrm{I}, \mathrm{J})$. The largest spinous process, a characteristic of V9 (T2) vertebra in wild-type mice, was present at V10 (T3) in ActRIIB ${ }^{-1-}$ mice (Fig. 5K,I). The shape of the spinous process in wild-type mice changes at V16 (T9) and V17 (T10), but this transition of the shape occurred at V18 (T11) and V20 (T12) in the mutant mice (Fig. 5E-H). The spinous process of V19 in mutant mice pointed in the posterior direction although its shape looked similar to V17 in wild type (Fig. 5G,H, arrowhead in H). The last pair of thoracic ribs are attached to V20 in the wild-type mice but to V23 in the ActRIIB ${ }^{-1-}$ mice (Fig. 5E,F). The above comparison of morphological changes of the vertebrae between wild-type and mutant mice indicated that a series of anterior transformation occurred at multiple places in the thoracic vertebrae of the mutant mice (Fig. 6G).

Precise regulation of Hox gene expression boundaries and levels is critical for specification of segment identity (for review, see Manak and Scott 1994). In recent years numerous reports have described homeotic transformation of the vertebrae induced by ectopic expression or targeted disruption of Hox genes (for review, see Stein et al. 1996). To examine whether the homeotic transformation of the axial skeleton in ActRIIB ${ }^{-1-}$ mice was associated with alteration in Hox expression, we examined the expression of several Hox genes including Hoxc-6, Hoxc-8, Hoxc-9, and Hoxc-10 in ActRIIB ${ }^{-1-}$ embryos by whole-mount in situ hybridization. No significant changes in Hox expression levels were detected. However, the anterior boundaries of all four Hox genes were shifted in the posterior direction. To determine the expression domain of each Hox gene, the segmented prevertebrae of E12.5 embryos were visualized by wholemount in situ hybridization with a type II collagen probe for cartilage. The cervical, thoracic, and lumbar vertebrae were distinguishable by the primitive ribs attached to the thoracic vertebrae (Fig. 6A,B). The prevertebral pattern showed that the ActRIIB ${ }^{-/-}$embryos had 16 primitive ribs, whereas the wild-type littermates had only 13 . The Hox gene expression domains were then determined by superimposing the Hox gene expression pattern to that of the type II collagen. The Hoxc- 6 expression was detected within the thoracic region, in segments from prevertebra V8 (T1) to V15 (T8) in the wild type (Fig. 6C). In the mutant embryos, the anterior boundary was shifted to V9 (T2) and the posterior boundary to V18 (T11) (Fig. 6D). Similarly, Hoxc-8 was detected in segments from V13 (T6) to V18 (T11) in the wild type but from V14 (T7) to V20 (T13) in ActRIIB ${ }^{-1-}$ embryos (Fig. 6E,F). In wild-type embryos, the anterior boundaries of the Hoxc-9 and Hoxc-10 expression domains were at V19 (T12) and V22 (L2), respectively. In the mutant embryos, the anterior boundaries of both Hoxc-9 and Hoxc-10 were shifted posteriorly by three vertebrae to V22 (T15) and V25 (L2), respectively (data not shown). Figure 6G summarizes the changes of Hox gene expression patterns and the alterations of the vertebral segment identity.

\section{Synergistic effects of RA-treatment and ActRIIB mutation on vertebral patterning}

Exposure of E8.5 embryos to a low dose of retinoic acid [(RA) all-trans, $10 \mathrm{mg} / \mathrm{kg}$ of body weight] induces anterior transformation of the vertebrae, showing C7/T14/ L6 $(85 \%)$ or C7/T15/L5 (9\%) vertebral patterns (Kessel and Gruss 1991). This RA-induced vertebral defect is similar to, but less severe than, that of $\mathrm{ActRIIB}^{-/-}$mice. In addition to the vertebral transformations, the administration of RA can exert a wide variety of teratogenic effects on developing embryos, including defects in cardiac outflow tract (TGA or DORV) (Yasui et al. 1995) and pulmonary isomerism (Kim et al. 1995). RA treatment can also alter Hox gene expression patterns during development (for review, see Conlon 1995). The remarkable similarities between RA-induced defects and the ActRIIB $^{-1-}$ phenotypes raises the possibility that RA and ActRIIB might act in the same genetic pathway. One possible mechanism by which RA induces anterior 


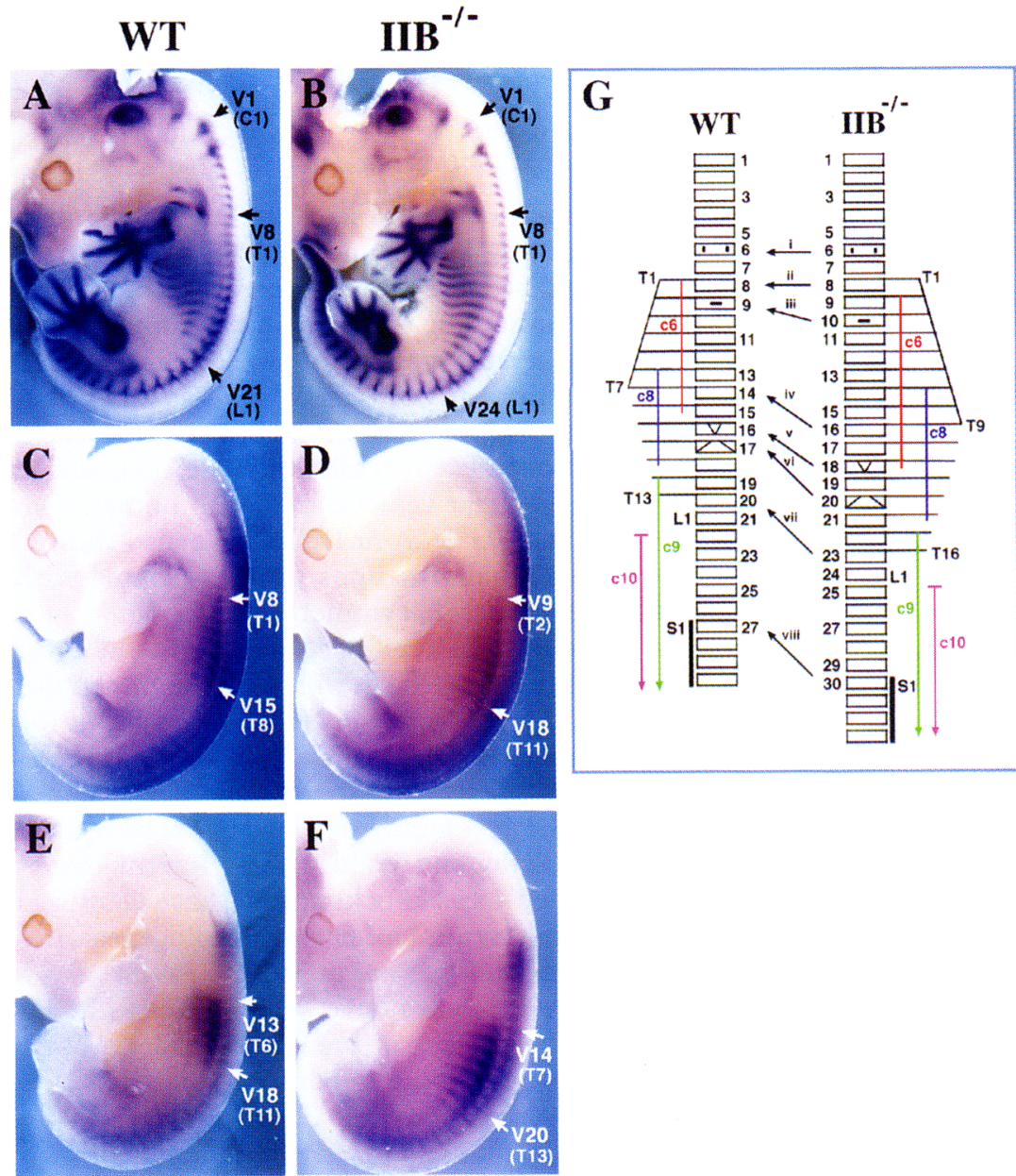

Figure 6. Hox gene expression in E12.5 embryos. $(A, B)$ In situ hybridization of E12.5 wild-type (WT) and ActRIIB ${ }^{-1-}\left(\mathrm{IIB}^{-/-}\right)$embryos with a type II collagen probe that detects the prevertebral structures. The thoracic vertebrae can be identified by the attachment of the growing rib cartilage. Note that the vertebral pattern in the wild-type and ActRIIB ${ }^{-1}$ embryos is completely established by E12.5. $(C, D)$ The expression pattern of Hoxc- 6 and $(E, F)$ the expression pattern of Hoxc-8 in wildtype and ActRIIB ${ }^{-1-}$ embryos. Arrows indicate the boundaries within which Hox gene expression is detected. $(G)$ A diagram summarizing the anterior transformation of the axial vertebrae and the posterior shift of the Hox gene expression domain in ActRIIB $^{-/-}$mice. The arrows indicate some conserved morphological markers between wild-type and mutant embryos: (i) tuberculi anterior; (ii) the first vertebrosternal rib; (iii) the largest spinous process; (iv) the last vertebrosternal rib; $(\mathrm{v})$ the last vertebrae with a caudally extending spinous process; (vi) The first vertebra with an anteriorly extending spinous process; (vii) the last rib attachment; (viii) the first sacral vertebra. Note an increase of one vertebra between ii and iii, iii and iv, $\mathrm{v}$ and vi in the mutant embryo. The expression domain of each Hox gene is indicated by the gene name and a vertical line. The vertical arrows for Hoxc- 9 and Hoxc-10 indicate no posterior boundaries. (V) Vertebrae; (T) thoracic vertebrae; (L) lumbar vertebrae; (S) sacral vertebrae. transformation of the vertebrae is to partially block the ActRIIB signaling pathway, for example, by altering the expression level or pattern of the ligand, thus mimicking the inactivation of the ActRIIB gene. If so, we would expect that RA treatment would have no additional effect on ActRIIB ${ }^{-/-}$fetuses, as the mutant phenotype of ActRIIB $^{-/-}$embryos would represent the maximum effect of RA, and, meanwhile, the mutation would render ActRIIB $^{+/}$embryos more sensitive to RA than the wildtype littermates. To test this hypothesis we analyzed the effects of RA exposure to the wild-type, ActRIIB ${ }^{+/-}$, and ActRIIB $^{-1-}$ embryos.

It has been shown that the diverse teratogenic effects on embryos by RA exposure depend on the developmental stage when RA is administered and the dosage of RA (Yasuda 1986; Kessel and Gruss 1991; Kessel 1992). We chose to use a low dose (10 mg of all-trans RA $/ \mathrm{kg}$ of body weight) to treat E8.5 embryos because under this condition RA almost exclusively affects the patterning of the vertebrae without any effect on the development of the heart, lung, and other visceral organs as well as craniofacial bones. A single administration of RA was given to the pregnant mice through oral gavage at 8.5 days of pregnancy. The embryos exposed to RA were dissected out at E18.5 by cesarean section, and the visceral organs were examined prior to skeleton preparation for staining with alcian blue and alizarin red. Of 67 wild-type and heterozygous fetuses examined, no significant difference in the vertebral pattern was observed. The most frequent vertebral pattern of both wild-type and $\mathrm{ActRIIB}^{+/-}$fetuses exposed to RA were C7/T14/L6 with seven or eight vertebrosternal ribs (Fig. 7A; Table 2). In contrast, the ActRIIB ${ }^{-1-}$ littermates exposed to RA showed further increase of the thoracic vertebrae up to 19 . The most common vertebral pattern of RA-treated ActRIIB ${ }^{-1-}$ fetuses was $\mathrm{C} 7 / \mathrm{T} 18 / \mathrm{L} 6$ with 10 vertebrosternal ribs (Fig. $7 \mathrm{~B}$; Table 2). Interestingly, of 15 such treated fetuses, 12 showed complete absence of caudal vertebrae, among which 4 did not even have sacral bones. Most of the RA-treated ActRIIB ${ }^{-/-}$mice also showed spinal bifida from the caudal end of the thoracic to the entire lumbar vertebrae (Fig. 7B,C). The shortening or absence of the caudal vertebrae and spinal bifida were observed in the wild-type embryos only when 5-10 times higher dosage of RA (50-100 mg/ $\mathrm{kg}$ of mouse) was used (Yasuda 1986; Kessel 1992). Taken together, these results showed that the ActRIIB mutation and RA treatment had synergistic effects on vertebral patterning. 


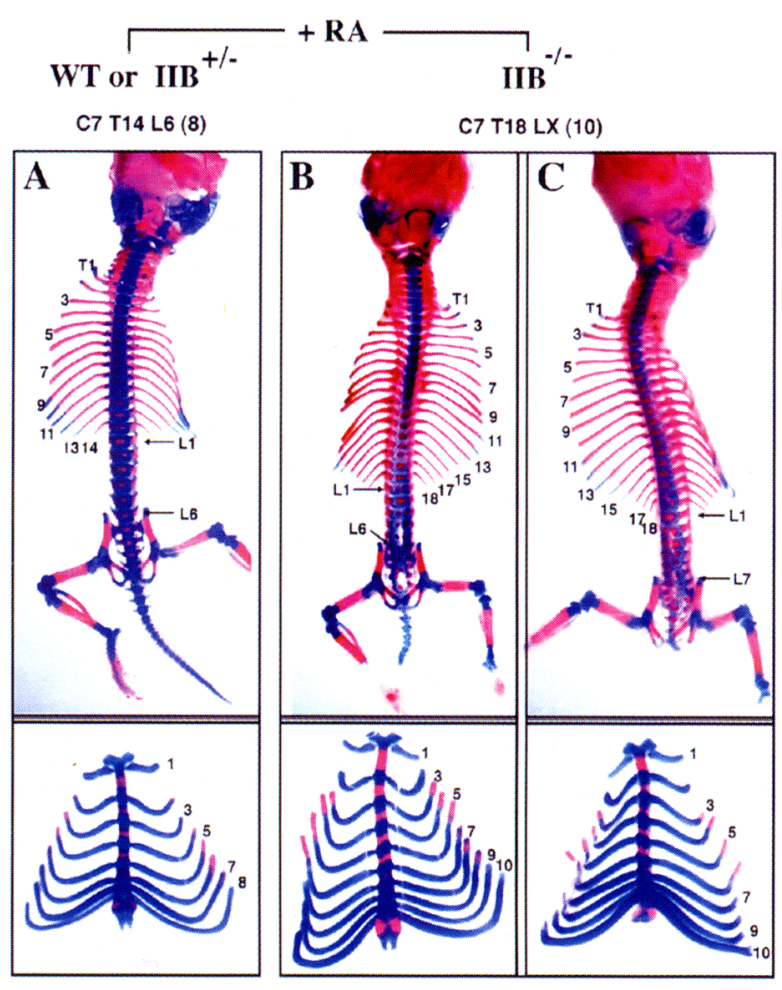

Figure 7. Synergistic effects of RA and ActRIIB mutation on vertebral patterning. Axial skeleton of wild-type/heterozygous and ActRIIB ${ }^{-1-}$ fetuses exposed to RA at E8.5 of gestation are shown by ventral view of the entire vertebral column (top) and the vertebrosternal (VS) ribs (bottom). Clavicular and forelimbs were removed, and the rib cage was cut open. (A) Representative patterns of wild-type or ActRIIB $^{+/-}$vertebrae that contain 14 complete ribs, 8 VS ribs, and 6 lumbar vertebrae. The sacral and caudal vertebrae are normal. $(B, C)$ Representative patterns of ActRIIB $^{-/-}$vertebrae, including 18 complete ribs, 10 VS ribs, and 6 or 7 lumbar vertebrae (also see Table 2). Note the shortening $(B)$ and the absence $(C)$ of the tail and the bifurcation of the lumbar vertebrae $(B, C)$. Numbers in parenthesis represent the numbers of the vertebrosternal ribs.

\section{Discussion}

To elucidate the function of the type IIB activin receptor during mouse development, we have disrupted the ActRIIB gene by homologous recombination. We found that mice homozygous for the mutation developed to term but died shortly after birth owing to complicated heart defects. The mutant mice showed malposition of the heart, abnormal patterning of the outflow tract, RPI, splenic and renal defects, and homeotic transformation of the vertebral column. These results indicate that ActRIIB plays a crucial role in patterning along the anteroposterior and left-right body axes and in organogenesis. The survival of the ActRIIB ${ }^{-/-}$embryos to birth suggests that ActRIIB is not essential for mesoderm formation and gastrulation. However, this should not be interpreted as a lack of function of the type II receptors in early development. The development of ActRIIA A $^{-/}$ ActRIIB $^{-/-}$double mutant embryos was arrested before gastrulation, indicating overlap function of the two type II receptors in early development (S.P. Oh and E. Li, unpubl.).

\section{Congenital cardiac malformations}

Cardiac malformations represent the most common form of human birth defects and are well characterized anatomically and physiologically. However, the genetic basis for most cardiac anomalies is largely unknown. In this study we showed that disruption of the ActRIIB gene resulted in three major types of cardiac malformations: (1) randomized positions of the heart and descending aorta, (2) atrial and ventricular septal defects, and (3) malposition of the great vessels, similar to human congenital defects such as TGA or DORV. We also showed that these cardiac malformations were associated with the disturbance of lateral asymmetry.

Studies in chick have demonstrated that neural crest cells derived from a specific region of the neural tube, known as cardiac neural crest (CNC), participate in the formation of the outflow tract and the septum of the heart. It has been shown that the complete ablation of CNC results in PTA, a failure of septation between the Ao and the PT (Kirby and Waldo 1995). Recent efforts using both transgenic and knockout mice have identified $>20$ genes that are essential for normal cardiogenesis (for review, see Olson and Srivastava 1996; Rossant 1996), among which several genes have been shown to be involved in the development of the outflow tract. Mouse embryos lacking the neurofibromatosis type-1 (NF-1) or Pax3 gene (Splotch) die around E13.5 and show PTA (Franz 1989; Brannan et al. 1994). Mice lacking both RA receptors $\alpha$ and $\beta 2\left(\mathrm{RAR}^{-/-} \beta 2^{-/-}\right)$also showed PTA and ventricular septal defects (Mendelsohn et al. 1994). To date, no genetically altered mice have shown TGA or DORV, making the ActRIIB ${ }^{-/-}$mice unique for studying related human congenital heart malformations. In humans, the cardiac defects associated with right isomerism are particularly severe, which often lead to early postnatal lethality. With the ActRIIB ${ }^{-1-}$ mouse model, it is now possible to study the embryonic defects in morphogenetic processes such as heart looping and patterning or migration of CNC and to understand the etiology of congenital heart defects in humans.

Determination of left-right asymmetry: isomerism vs. situs inversus

In vertebrates, the visceral organs are asymmetric in position or shape along the left-right (L-R) axis, and the asymmetry is handed, not random. In mice, the heart is on the left side of the chest with the apex pointing to the left; the descending aorta loops to the left; the right lung has four lobes, whereas the left lung has one lobe; and the stomach and spleen lie on the left side in the abdomen. How these handed asymmetries are generated during embryonic development is largely unknown.

Two major types of disturbances of L-R asymmetry have been observed in humans and mice. One type is 
known as "situs inversus," a condition in which the L-R asymmetry of internal organs is simply reversed. The human Kartagener's syndrome (Kartagener and Stucki 1962) and mouse mutants iv (for inversus viscerum) (Hummel and Chapman 1959) and inv (for inversion of embryonic turning) (Yokoyama et al. 1993) display situs inversus. The other type of defect in lateral asymmetry is termed "isomerism," in which some normally asymmetric visceral organs acquire bilateral symmetry. In humans this type of disorder has been known by many terms including isomerism sequence, situs ambiguus, and visceral heterotaxy owing to the complexity of the clinical symptoms and is associated with diseases such as Ivemark's syndrome and asplenia/polysplenia syndrome (for review, see Burn 1991). The clinical manifestations in the right isomerism includes bilateral trilobed lungs, short eparterial bronchi and right atrial appendages, and absence or hypoplasia of the spleen. On the other hand, the left isomerism is associated with bilaterally bilobed lungs, long hyparterial bronchi, left atrial appendages, and multiple spleens. Both right and left isomerisms are also associated with complex cardiac defects (Van Praagh et al. 1992; Perloff 1994; Phoon and Neill 1994). In this study we showed that the ActRIIB ${ }^{-/-}$ mutant mice had bilaterally tetralobed lungs and symmetrical bronchi, bilateral right atrial appendages, splenic abnormalities, and complex cardiac anomalies including malposition of the heart and the outflow tract. These phenotypes are reminiscent of the clinical symptoms of the human asplenia syndrome (right isomerism), suggesting that the human syndrome may be caused by defects in the ActRIIB signaling pathway. The $A c t R I I B^{-1-}$ mice thus represent a useful animal model for the human disease, with which the underlying molecular mechanism can now be investigated.

The relationship between isomerism and situs inversus is quite peculiar. A significant proportion of the $i v^{-/}$ mice show right or left isomerism (Icardo and Sanchez de Vega 1991; Seo et al. 1992; Layton et al. 1993) and similarly, situs inversus, right or left isomerism can also coexist within the same kindred in human (Brueckner et al. 1991; Burn 1991), suggesting that these different types of laterality defects might be caused by alterations in the same gene or in the same genetic pathway. While the right pulmonary isomerism and cardiac defects displayed by some $i \mathrm{~V}^{-1-}$ mice are phenotypically similar to the defects in $\mathrm{ActRIIB}^{-1-}$ mutants, situs inversus or left isomerism has never been observed so far in ActRIIB ${ }^{-/-}$mice. To understand the relationship between the ActRIIB and iv mutations, it would be interesting to test genetic epistasis between ActRIIB and iv or inv by interbreeding ActRIIB $^{-1-}$ with iv or inv mice and to examine the phenotype of the double mutants.

A molecular pathway determining L-R asymmetry has been proposed based on the study of asymmetric expression of several signaling molecules during chick embryogenesis (Levin et al. 1995). It shows that the right-side expression of activin represses Sonic hedgehog $(S h h)$ on the right side, and $S h h$ expression on the left induces left-side expression of $c N R-1$, a chick homolog of nodal, and establishes lateral asymmetry (Levin et al. 1995). Recently, several more genes including $c S n R$ (snail-related zinc finger gene), activin $\beta B$, and follistatin have been shown to exibit L-R asymmetric expression in chick embryos (Isaac et al. 1997; Levin 1997). In Xenopus, it has been shown that Vg-1 and Xnr-1 (nodal related) are involved in the establishment of L-R asymmetry (Hyatt et al. 1996). Interestingly, injection of the truncated ActRIIB receptor tXAR into the dorsal-left side of 16-cell embryos also randomizes the heart situs, presumably by blocking the maternal Vg-1 or Vg-1-like signals (Hyatt et al. 1996). In mice it has been shown that two TGF- $\beta$ family members, nodal and lefty, are expressed only on the left side in the lateral plate mesoderm during early somite stages, and this asymmetric pattern of expression is altered in $\mathrm{iv}^{-/-}$and $\mathrm{inv}^{-/-} \mathrm{em}-$ bryos (Collignon et al. 1996; Lowe et al. 1996; Meno et al. 1996). Whether the genetic pathway determining L-R asymmetry is conserved among different vertebrate species remains to be seen.

One important conclusion drawn from these studies is that the TGF- $\beta$ family signaling molecules, such as activin, $\mathrm{Vg}-1$, and nodal, play a pivotal role in determining the L-R asymmetry. These molecules act in two different stages in a developmentally regulated process that produces L-R asymmetry. In the first stage, an activin or Vg-1-like signaling molecule becomes asymmetrically localized with respect to the L-R axis, which later determines the asymmetric expression of downstream signaling molecules such as nodal. The iv and inv genes are probably involved in this initial establishment of L-R asymmetry. In the second stage, the thoracic and abdominal organ primordia make the L-R choice under the instruction of the asymmetrically expressed signaling molecules. ActRIIB, which functions as a TGF- $\beta$ family receptor, may mediate signals in either stage or in both stages. If ActRIIB is the receptor for the activin or Vg-1like signaling molecule, the inactivation of ActRIIB would disrupt the asymmetric expression pattern of the downstream genes. On the other hand, ActRIIB could be involved in the interpretation of the asymmetric signals if it functions as a receptor for the downstream signaling molecules. Analysis of nodal and lefty expression in ActRIIB-mutant embryos will provide some insights into the specific role of ActRIIB in the signaling cascade of L-R determination.

\section{ActRIIB and RA signaling pathways in patterning the axial skeletons}

Vertebrate animals have segmented axial skeletons that can be divided into cervical, thoracic, lumbar, sacral, and caudal vertebrae. The mechanism by which each segment along the anteroposterior axis attains its identity has been explained by the "Hox code" hypothesis that a combination of functionally active Hox genes specifies the identity or morphology of individual vertebrae (Kessel and Gruss 1990, 1991). In recent years, numerous reports have described the changes of vertebral patterns by ectopic expression or mutation of the Hox genes (for 
review, see Krumlauf 1994; Manak and Scott 1994; Stein et al. 1996), supporting the Hox code hypothesis. However, it is largely unknown what signaling molecules are involved in providing the positional cues for setting up the "code" during normal development. We show in this study that disruption of the ActRIIB gene results in altered expression of multiple Hox genes and anterior transformation of the vertebrae, thus providing genetic evidence that the signaling pathway mediated by ActRIIB is involved in anteroposterior (A-P) patterning of the Hox genes during normal embryonic development.

The majority of $A c t R I I B^{-/-}$mice showed an increase of three thoracic vertebrae without numeric changes of the lumbar and sacral vertebrae. This abnormal vertebral pattern (C7/Tl6/L6) may be formed as a result of homeotic transformation along the entire vertebral column from thoracic to caudal vertebrae. Alternatively, the expansion of the thoracic vertebrae may be caused by the addition of three vertebral segments to the thoracic region without affecting the lumbar to caudal vertebrae. The vertebral patterning defects in $A c t R I I B^{-/-}$mice are more complex than many single Hox gene knockout mutants (e.g., Hoxc-8, Mouellic et al. 1992; and Hoxc-9, Suemori et al. 1995), suggesting that the ActRIIB signaling pathway may function as a global regulator in patterning the axial structure. The posterior shift of the anterior expression boundary of Hox genes correlates with the anterior transformation at multiple places of the thoracic vertebrae, and the expansion of the Hoxc-6 and Hoxc-8 expression domain may account for the addition of the vertebrae in mutant mice (see Fig. 6G). Transposition of vertebral patterns by the addition or deletion of some vertebral segments in vertebrate animals has been proposed to be determined by the expression boundaries of multiple Hox genes (Burke et al. 1995).

Although it requires further studies to elucidate how the ActRIIB signaling pathway might regulate A-P patterning of the vertebrae and which TGF- $\beta$ family ligands interact with the ActRIIB receptor, we would like to provide some explanations as to how the ActRIIB mutation might cause homeotic transformation of the vertebrae. First, it is possible that disruption of the ActRIIB singling pathway may result in some subtle defects in mesoderm patterning during early development, which may lead to abnormal vertebral patterning later in development. There is evidence that ActRIIB is involved in early mesoderm patterning as the ActRIIA/ActRIIB double mutants display severe defects in primitive streak formation (S.P. Oh and E. Li, unpubl.). A similar case has been described for the mouse eed mutants in which the null mutation of eed results in the disruption of A-P patterning of the primitive streak during gastrulation, whereas a hypomorphic mutation leads to homeotic transformation of the axial skeleton (Faust et al. 1995; Schumacher et al. 1996). The possible links between early mesoderm patterning and subsequent axial skeleton development remain to be determined.

The second possibility is that the ActRIIB signaling pathway may be required for proper expression of Hox genes in the somites. Although no direct evidence is available to support this hypothesis, it has been shown that ActRIIB is expressed in somites in E8.5 embryos (Feijen et al. 1994; S.P. Oh and E. Li, unpubl.). It has been shown that the sclerotome is induced by notochord and floorplate-derived signals, such as Shh (Fan and TessierLavigne 1994; Fan et al. 1995), and interestingly, Shh can induce expression of bone morphogenetic proteins (BMPs) and activate genes of the HoxD complex during limb patterning (Francis et al. 1994; Laufer et al. 1994). It is, therefore, tantalizing to speculate that BMPs induced by Shh might be also involved in sclerotome differentiation and patterning along the A-P axis by signaling through the type II activin receptors (see below).

Finally, it is also possible that ActRIIB might be involved in regulation of expression of the trithorax group (trxG) and the Polycomb group $(P C G)$ genes, thus playing a role in maintaining the Hox expression pattern. In Drosophila the Hox gene expression patterns have been shown to be maintained during development by the trx $G$ and $P C G$ genes (for review, see Simon 1995). The function of trxG and PcG appears to be conserved in mice. Inactivation of the $P c G$ genes such as $M 33$, mel-18, bmi1 , and eed results in the anterior shift of the expression domain of multiple Hox genes and the posterior transformation of the vertebrae (van der Lugt et al. 1994; Akasaka et al. 1996; Schumacher et al. 1996; Coré et al. 1997), whereas overexpression of bmi-1 causes a dosedependent anterior transformation of the vertebrae (Alkema et al. 1995). In addition, the inactivation of a murine homolog of the $\operatorname{trx} G, M 11$, results in both anterior and posterior transformation (Yu et al. 1995).

Embryonic exposure to RA at E8.5 and E7.5 induces anterior and posterior transformations of the vertebrae, respectively (Kessel and Gruss 1991), and RA treatment can alter Hox gene expression along the A-P axis (Conlon 1995). RA has been shown to directly activate some Hox genes through its nuclear receptors, which are transcription factors (Langston and Gudas 1992; Marshall et al. 1994; Ogura and Evans 1995). Various RAR knockout mutants exhibit homeotic transformation of the vertebrae, suggesting that RA is involved in vertebral patterning in vivo (Lohnes et al. 1994). The remarkable similarities between RA-induced vertebral defects and the ActRIIB ${ }^{-/-}$phenotypes (see Table 2) raise the possibility that RA may exert its effect by blocking the ActRIIB signaling pathway. Our analysis of RA-treated wild-type and ActRIIB-deficient mice showed that RA and the ActRIIB mutation had synergistic effects on vertebral patterning from thoracic to caudal vertebrae (Fig. 7; Table 2). This result suggests that RA is unlikely to act exclusively through the ActRIIB signaling pathway. The extensive functional overlap in embryonic development between ActRIIA and ActRIIB (S.P. Oh and E. Li, unpubl.) further suggests that the synergistic effect of RA on vertebral patterning in ActRIIB ${ }^{-1-}$ mice could be mediated by the ActRIIA receptor. Alternatively, it is possible that RA and ActRIIB may act on the same set of downstream target genes but through completely independent pathways. As RA exerts its effect at the early somite stage (E8.5), the synergy between RA and ActRIIB 
mutation on vertebral patterning suggests that ActRIIB may function around the same stage.

\section{ActRIIB may interact with multiple ligands of the TGF- $\beta$ family in vivo}

ActRIIA and ActRIIB have been shown to bind to activin specifically in cell culture system and are believed to mediate activin signals during normal development (for review, see Mathews 1994). However, to our surprise, none of the phenotypes observed in the ActRIIB-deficient mice, including cardiac malformation, pulmonary isomerism, renal defects, splenic abnormalities, and homeotic transformation of the vertebrae, were related to the defects observed in the activins A and B double knockouts (Matzuk et al. 1995a). Although it cannot be completely ruled out that maternal activins may compensate some of the embryonic defects in activin-deficient mice, the complex phenotypes of the ActRIIB mutants suggest that the ActRIIB receptor probably transduces signals of a number of different TGF- $\beta$ family ligands during normal development.

Although $>40$ members of the TGF- $\beta$ family have been identified in the vertebrates, only a small number of type I and type II receptors have been cloned so far (for reviews, see Kingsley 1994; Massagué 1996), suggesting that some receptors probably interact with multiple ligands during development. Among the known type II receptors, the Müllerian-inhibiting substance (MIS) type II receptor has been shown to interact solely with MIS in vivo as demonstrated by targeted mutation of the receptor, which results in identical defects as the MIS mutation (Behringer et al. 1994; Mishina et al. 1996). The TGF- $\beta$ type II receptor interacts with the TGF- $\beta$ subfamily specifically with little or no cross-reactivity to other factors (Lin et al. 1992), and both TGF- $\beta 1$ and TGF- $\beta$ type II receptor knockout mutants showed defective hematopoiesis and vasculogenesis (Dickson et al. 1995; Oshima et al. 1996). In contrast, the type II activin receptors appear to interact with multiple ligands in vitro as well as in vivo. In addition to activins, the type II activin receptors can also bind BMP-7 (Liu et al. 1995; Yamashita et al. 1995) and can mediate BMP-4 signaling during mesoderm formation in Xenopus (Chang et al. 1997). BMPs was detected in developing kidneys in mice (Dudley and Robertson 1997), correlated with our finding that kidney morphogenesis was affected in $\mathrm{ActRIIB}^{-/-}$ mice. Moreover, the receptors for many TGF- $\beta$ members such as $\mathrm{Vg}-1$, nodal, or lefty have yet to be identified. To this end, it should be noted that ActRIIB has four isoforms resulting from alternative splicing, which bind to activin with different affinities in vitro (Attisano et al. 1992). It is plausible that these isoforms may interact with a diverse range of ligands during development, and specific interactions are achieved by spatial and temporal regulation of expression of both ligands and the ActRIIB isoforms. Further genetic analysis of ligand and receptor mutants and biochemical studies of ligand-receptor interactions are required to determine the physiological ligands for the ActRIIB receptors.

\section{Materials and methods}

\section{Construction of the targeting vector}

A $10.5-\mathrm{kb}$ EcoRI fragment corresponding to the ActRIIB locus was isolated from $129 / \mathrm{Sv}$ genomic library (Strategene) and subcloned into the EcoRI site of a plasmid pGEM-11Zf(-). A 1.4-kb SmaI-ApaI fragment containing two coding exons was deleted and replaced by a phosphoglycerokinase (PGK)-neo-poly(A) cassette (the XhoI-SaII fragment from pKJ-1) through blunt-end ligation. The targeting vector contains $3-\mathrm{kb}$ homologous DNA on the left and $6-\mathrm{kb}$ homologous DNA on the right of the neomycin cassette (Fig. 1). The neo ${ }^{\mathrm{r}}$ cassette is placed in the same transcriptional orientation as the ActRIIB gene.

\section{Generation of germ-line chimeras with targeted mutation}

The J1 ES cells were transfected with a linearized vector by electroporation and were selected in G418-containing medium as described (Li et al. 1992). The genotype of G41 $8^{r}$ clones was analyzed by Southern blot hybridization using the R-X genomic fragment as a probe (See Fig. 1A). Of 174 G418-resistant ES cell clones analyzed for the homologous recombination, 1 contained the corrected targeting event and was injected into C57BL/6J blastocysts to obtain chimeric mice as described previously ( $\mathrm{Li}$ et al. 1992). Male chimeric mice transmitting the mutant gene through the germ line were bred either to $\mathrm{C} 57 \mathrm{Bl} / 6 \mathrm{~J}$ mice to obtain heterozygous F1 progeny or to $129 /$ Sv females to establish an inbred strain.

\section{Genotype analysis}

Genotypes were determined by Southern blot hybridization or PCR analysis. Genomic DNA isolated from mouse tails at weaning age was digested with $\mathrm{BamHI}$, blotted, and probed with the random primed R-X genomic fragment (Fig. 1) as described previously ( $\mathrm{Li}$ et al. 1992). To detect the wild-type allele by PCR, a set of primers was chosen, corresponding to the exon that is deleted in the targeting vector: $5^{\prime}$ oligonucleotide $\left(5^{\prime}\right.$-CCGACAGCCCCCACCCTGCTCA-3'), 3' oligonucleotide (5'-GGCCCACCAGAGGGGATGGGG-3'). A 241-bp DNA fragment was amplified by this primer pair from wild-type and $\mathrm{ActRIIB}^{+/-}$ DNA but not from ActRIIB ${ }^{-/-}$DNA. A pair of primers corresponding to the neomycin-resistance gene was used to amplify a 600-bp fragment from ActRIIB ${ }^{+/-}$and ActRIIB-/- DNA: $5^{\prime}$ oligonucleotide (5'-ATGAACTGCAGGACGAGGCAGCG-3'), $3^{\prime}$ oligonucleotide (5'-GGCGATAGAAGGCGATGCGCTG- $\left.3^{\prime}\right)$. Both sets of primers were used in the same PCR reaction with annealing temperature at $70^{\circ} \mathrm{C}$.

\section{Administration of $R A$ and skeletal preparation}

All-trans RA (Sigma) was dissolved in DMSO at $12.5 \mathrm{mg} / \mathrm{ml}$ (RA/DMSO) and stored at room temperature in the dark. The RA/DMSO stock was subjected to a 10-fold dilution in sesame oil and administered to the pregnant mice at 8.5 days of gestation at a final concentration of $10 \mathrm{mg} / \mathrm{kg}$ of body weight through oral-gavage needle. The embryos were collected from the female mice at E18.5, and skeletons were stained by alizarin red-alcian blue (Zhang et al. 1995). The embryos were eviscerated and left in water overnight with gentle shaking. On the following day, skin, fat, muscle, and glands were removed. After being washed in water briefly, the embryos were fixed in $95 \%$ ethanol for 2-5 days with gentle shaking. The fixed embryos were stained with alcian blue $8 \mathrm{GX}(0.15 \mathrm{mg} / \mathrm{ml})$ in $80 \%$ ethanol and $20 \%$ glacial acetic acid for $8 \mathrm{hr}$ to overnight. After washing with $95 \%$ ethanol several times, the tissue was cleared in $2 \% \mathrm{KOH}$ for $3 \mathrm{hr}$. 
Then, $1 \%$ alizarin red S (Sigma) was added to the final concentration of $0.005 \%$. After $3 \mathrm{hr}$ of staining, the embryos were rinsed twice with $2 \% \mathrm{KOH}$ and stored in $50 \%$ glycerol-PBS.

\section{Injection of the casting dye and histological analysis of} the heart

The sternum and the thymus of postnatal day 1 or E18.5 mice were removed. The casting dyes /Connecticut Valley Biological Supply Co.) were injected directly into the ventricles of the heart using a pulled capillary glass pipette. Yellow dye was injected into the right ventricle, followed by blue dye into the left ventricle. Histological analysis was carried out using standard methods. Embryos or tissues were fixed either in Bouin's fixative (Polyscience) or $4 \%$ paraformaldehyde at $4^{\circ} \mathrm{C}$ overnight, dehydrated in a series of ethanol, cleared in xylene substitute, and embedded in paraffin. Sections were cut at 6-7 $\mu \mathrm{m}$ and stained with hematoxylin and eosin.

Whole-mount in situ hybridization and analysis of Hox gene expression patterns

E12.5 embryos were dissected and fixed in $4 \%$ paraformaldehyde in PBS plus $0.1 \%$ Tween 20 at $4^{\circ} \mathrm{C}$ overnight. Yolk sac DNA was used for genotyping embryos. Antisense RNA probes were generated using digoxygenin UTP (Boehringer Mannheim). Whole-mount in situ hybridization was performed as described (Wilkinson 1992) The expression boundaries for the Hox gene were determined by the close comparison with the embryos probed with Col2Al. The photographs were taken under the same magnification, and the same size and same genotype embryos probed with Col2Al were superimposed on embryos probed with Hox genes, using the forelimb and hindlimb positions as reference.

\section{Acknowledgments}

We thank Mark Fishman, Kerri Warren, Bjorn Olsen, Barry Ticho, and members of our laboratory for discussion and critical reading of the manuscript. We are grateful to Mario Capecchi, Cliff Tabin, and Anne Burke for the Hox probes and Naomi Fukai for Col2Al probe. This work is supported by a grant from Bristol-Myers Squibb to E.L. S.P.O. is the recipient of a National Research Service Award (National Institutes of Health, 5 F32HD07945).

The publication costs of this article were defrayed in part by payment of page charges. This article must therefore be hereby marked "advertisement" in accordance with 18 USC section 1734 solely to indicate this fact.

\section{References}

Akasaka, T., M. Kanno, R. Balling, M.A. Mieza, M. Taniguchi, and H. Koseki. 1996. A role of mel-18, a Polycomb grouprelated vertebrate gene, during the anteroposterior specification of the axial skeleton. Development 122: 1513-1522.

Alkema, M.J., N.M.T. van der Lugt, R.C. Bobeldijk, A. Berns, and M. van Lohulzen. 1995. Transformation of axial skeleton due to overexpression of bmi-l in transgenic mice. $\mathrm{Na}$ ture 374: 724-727.

Anderson, R.H., S. Webb, and N. Brown. 1996. Establishing the anatomic hallmarks of congenitally malformed hearts. Trend Cardiac Med. 6: 10-15.

Attisano, L., J.L. Wrana, S. Cheifetz, and J. Massagué. 1992. Novel activin receptors: Distinct genes and alternative
mRNA splicing generate a repertoire of Serine/Thereonine kinase receptors. Cell 68: 97-108.

Attisano, L., J. Carcamo, F. Ventura, F.M.B. Weis, J. Massagué, and J.L. Wrana. 1993. Identification of human activin and TGF-beta type I receptors that form heteromeric kinase complexes with type II receptors. Cell 75: 671-680.

Attisano, L., J.L. Wrana, E. Montalvo, and J. Massagué. 1996. Activation of signaling by the activin receptor complex. Mol. Cell. Biol. 16: 1066-1073.

Behringer, R.R., M.J. Finegold, and R.L. Cate. 1994. Müllerianinhibiting substance function during mammalian sexual development. Cell 79: 415-425.

Brannan, C.I., A.S. Perkins, K.S. Vogel, N. Ratner, M.L. Nordlund, S.W. Reid, A. Buchberg, N.A. Jenkins, L.F. Parada, and N.G. Copeland. 1994. Targeted disruption of the neurofibromatosis type-1 gene leads to developmental abnormalities in heart and various neural crest-derived tissues. Genes \& Dev. 8: 1019-1029.

Brueckner, M., J. McGrath, P. D'Eustachio, and A. Horwich. 1991. Establishment of left-right asymmetry in vertebrates: Genetically distinct steps are involved. Biological asymmetry and handedness. Ciba Found. Symp. 162: 202-218.

Burke, A.C., C.E. Nelson, B.A. Morgan, and C. Tabin. 1995. Hox genes and the evolution of vertebrate axial morphology. Development 121: 333-346.

Burn, J. 1991. Disturbance of morphological laterality in humans. Biological asymmetry and handedness. Ciba Found. Symp. 162: 282-299.

Chang, C., P.A. Wilson, L.S. Mathews, and A. Hemmati-Brivanlou. 1997. A Xenopus type I activin receptor mediates mesodermal but not neural specification during embryogenesis. Development 124: 827-837.

Chen, X., M.J. Rubock, and M. Whitman. 1996. A transcriptional partner for MAD proteins in TGF- $\beta$ signalling. Nature 383: 691-696.

Collignon, J., I. Varlet, and E.J. Robertson. 1996. Relationship between asymmetric nodal expression and the direction of embryonic tunring. Naure 381: 155-158.

Conlon, R.A. 1995. Retinoic acid and pattern formation in vertebrates. Trends Genet. 11: 314-319.

Coré, N., S. Bei, S.J. Gaunt, M. Aurrand-Lions, J. Pearce, A. Fisher, and M. Djabali. 1997. Altered cellular proliferation and mesoderm patterning in polycomb-M33-deficient mice. Development 124: 721-729.

Derynck, R. and Y. Zhang. 1996. Intracellular signalling: The Mad way to do it. Curr. Biol. 6: 1226-1229.

Dickson, M.C., J.S. Martin, F.M. Cousins, A.B. Kulkarni, S. Karlsson, and R.J. Akhurst. 1995. Defective haematopoiesis and vasculogenesis in transforming growth factor- $\beta 1$ knock out mice. Development 121: 1845-1854.

Dudley, A.T. and E.J. Robertson. 1997. Overlapping expression domains of bone morphogenetic protein family members potentially account for limited tissue defects in BMP7 deficient embryos. Dev. Dynam. 208: 349-362.

Fan, C.-M. and M. Tessier-Lavigne. 1994. Patterning of mammalian somites by surface ectoderm and notochord: Evidence for sclerotome induction by a hedgehog homolog. Cell 79: 1175-1186.

Fan, C.-M., J.A. Porter, C. Chiang, D.T. Chang, P.A. Beachy, and M. Tessier-Lavigne. 1995. Long-range sclerotome induction by Sonic hedgehog: Direct role of the amino-terminal cleavage product and modulation by the cyclic AMP signaling pathway. Cell 81: 457-465.

Faust, C., A. Schumacher, B. Holdener, and T. Magnuson. 1995. The eed mutation disrupts anterior mesoderm production in mice. Development 121: 273-285. 
Feijen, A., M.J. Goumans, and A.J.M. van den Eijnden-van Raaij. 1994. Expression of activin subunits, activin receptors and follistatin in postimplantation mouse embryos suggests specific developmental functions for different activins. Development 120: 3621-3637.

Francis, P.H., M.K. Richardson, P.M. Brickell, and C. Tickle. 1994. Bone morphogenetic proteins and a signalling pathway that controls patterning in the developing chick limb. Development 120: 209-218.

Franz, T. 1989. Persistant truncus arteriosus in the Splotch mutant mouse. Anat. Embryol. 180: 457-464.

Hemmati-Brivanlou, A. and D.A. Melton. 1992. A truncated activin receptor inhibits mesoderm induction and formation of axial structure in Xenopus embryos. Nature 359: 609-614.

Hummel, K.P. and D.B. Chapman. 1959. Visceral inversion and associated anomalies in the mouse. J. Hered. 50:9-13.

Hyatt, B., J.L. Lohr, and J. Yost. 1996. Initiation of vertebrate leftright axis formation by maternal Vg1. Nature 384: 62-65.

Icardo, J.M. and M.J. Sanchez de Vega. 1991. Spectrum of heart malformations in mice with situs solitus, situs inversus, and associcated visceral heterotaxy. Circulation 84: 2547-2558.

Isaac, A., M.G. Sargent, and J. Cooke. 1997. Control of vertebrate left-right asymmetry by a snail-related zinc finger gene. Science 275: 1301-1304.

Kartagener, M. and P. Stucki. 1962. Bronchiectasis with situs inversus. Arch. Dis. Child. 79: 193-207.

Kessel, M. 1992. Respecification of vertebral identities by retinoic acid. Development 115: 487-501.

Kessel, M. and P. Gruss. 1990. Murine developmental control genes. Science 249: 374-379.

- 1991. Homeotic transformation of murine vertebrae and concomitant alteration of hox codes induced by retinoic acid. Cell 67: 89-104.

Kim, S.H., C.S. Son, J.W. Lee, Y.C. Tockgo, and Y.H. Chun. 1995. Visceral heterotaxy syndrome induced by retinoids in mouse embryo. J. Korean Med. Sci. 10: 250-257.

Kingsley, D.M. 1994. The TGF- $\beta$ superfamily: New members, new receptors, and new genetic tests of function in different organisms. Genes \& Dev. 8: 133-146.

Kirby, M. and K.L. Waldo. 1995. Neural crest and cardiovascular patterning. Circ. Res. 77: 211-215.

Krumlauf, R. 1994. Hox genes in vertebrate development. Cell 78: 191-201.

Langston, A.W. and L.J. Gudas. 1992. Identification of a retinoic acid responsive enhancer $3^{\prime}$ of the murine homeobox gene Hox-1.6. Mech. Dev. 38: 217-228.

Laufer, E., C.E. Nelson, R.L. Johnson, B.A. Morgan, and C. Tabin. 1994. Sonic hedgehog and Fgf-4 act through a signaling cascade and feedback loop to integrate growth and patterning of the developing limb bud. Cell 79: 993-1003.

Layton, W.M., M.W. Layton, M. Binder, D.M. Kurnit, A.J. Hanzlik, M. van Keuren, and F.G. Biddle. 1993. Expression of the IV (reversed and/or heterotaxic) phenotype in SWV mice. Teratology 47: 595-602.

Levin, M. 1997. Left-right asymmetry in vertebrate embryogenesis. BioEssays 19: 287-296.

Levin, M., R.L. Johnson, C.D. Stern, M. Kuehn, and C. Tabin. 1995. A molecular pathway determining left-right asymmetry in chick embryogenesis. Cell 82: 803-814.

Li, E., T.H. Bestor, and R. Jaenisch. 1992. Targeted mutation of the DNA methyltransferase gene results in embryonic lethality. Cell 69: 915-926.

Lin, H.Y., X.F. Wang, R.A. Ng, R.A. Weinberg, and H.F. Lodish. 1992. Expression cloning of the TGF-beta type II receptor, a functional transmembrane serine/threonine kinase. Cell 68: 775-785.
Liu, F., F. Ventura, J. Doody, and J. Massagué. 1995. Human type II receptor for bone morphogenic proteins (BMPs): Extension of the two-kinase receptor model to the BMPs. Mol. Cell. Biol. 15: 3479-3486.

Liu, F., A. Hata, J. Baker, J. Doody, J. Cárcamo, R. Harland, and J. Massagué. 1996. A human Mad protein acting as a BMPregulated transcriptional activator. Nature 381: 620-623.

Lohnes, D., M. Mark, C. Mendelsohn, P. Dollé, A. Dierich, P. Gorry, A. Gansmuller, and P. Chambon. 1994. Function of the retinoic acid receptors (RARs) during development: (I) Craniofacial and skeletal abnormalities in RAR double mutants. Development 120: 2723-2748.

Lowe, L.A., D.M. Supp, K. Sampath, T. Yokoyama, C.V.E. Wright, S.S. Potter, P. Overbeek, and M.R. Kuehn. 1996. Conserved left-right asymmetry of nodal expression and alterations in murine situs inversus. Nature 381: 158-161.

Manak, J.R. and M.P. Scott. 1994. A class act: Conservation of homeodomain protein functions. Development (Suppl.) 6171.

Manova, K., V. De Leon, M. Angeles, S. Kalantry, M. Giarré, L. Attisano, J. Wrana, and R.F. Bachvarova. 1995. mRNAs for activin receptors II and IIB are expressed in mouse oocytes and in the epiblast of pregastrula and gastrula stage mouse embryos. Mech. Dev. 49: 3-11.

Marshall, H., M. Studer, H. Pöpperl, S. Aparicio, A. Kuroiwa, S. Brenner, and R. Krumlauf. 1994. A conserved retinoic acid response element required for early expression of the homeobox gene Hoxb-1. Nature 370: 567-571.

Massagué, J. 1996. TGF- $\beta$ signaling: Receptors, transducers, and Mad proteins. Cell 85: 947-950.

Mathews, L.S. 1994. Activin receptors and cellular signaling by the receptor serine kinase family. Endocrinol. Rev. 15: 310325

Mathews, L.S. and W.W. Vale. 1991. Expression cloning of an activin receptor, a predicted transmembrane serine kinase. Cell 65: 973-982.

Matzuk, M.M., T.R. Kumar, A. Vassalli, J.R. Bickenbach, D.R. Roop, R. Jaenisch, and A. Bradley. 1995a. Functional analysis of activins during mammalian development. Nature 374: 354-356.

Matzuk, M.M., T.R. Kumar, and A. Bradley. 1995b. Different phenotypes for mice deficient in either activins or activin receptor II. Nature 374: 356-360.

Mendelsohn, C., D. Lohnes, D. Décimo, T. Lufkin, M. LeMeur, P. Chambon, and M. Mark. 1994. Function of retinoic acid receptors (RARs) during development: (II) Multiple abnormalities at various stages of organogenesis in RAR double mutants. Development 120: 2749-2771.

Meno, C., Y. Saijoh, H. Fuii, M. Ikeda, T. Yokoyama, M. Yokoyama, Y. Toyoda, and H. Hamada. 1996. Left-right asymmetric expression of the TGF $\beta$-family member lefty in mouse embryos. Nature 381: 151-155.

Mishina, Y., R. Rey, M.J. Finegold, M.M. Matzuk, N. Josso, R.L. Cate, and R.R. Behringer. 1996. Genetic analysis of the Müllerian-inhibiting substance signal transduction pathway in mammalian sexual differentiation. Genes \& Dev. 10: 25772587.

Mouellic, H.L., Y. Lallemand, and P. Brulet. 1992. Homeosis in the mouse induced by a null mutation in the Hox-3.1 gene. Cell 69: 251-264.

Ogura, T. and R.M. Evans. 1995. A retinoic acid-triggered cascade of HoxB1 gene activation. Proc. Natl. Acad. Sci. 92: $387-391$.

Olson, E.N. and D. Srivastava. 1996. Molecular pathways controlling heart development. Science 272: 671-676.

Oshima, M., H. Oshima, and M.M. Taketo. 1996. TGF- $\beta$ recep- 
tor type II deficiency results in defects of yolk sac hematopoiesis and vasculogenesis. Dev. Biol. 179: 297-302.

Perloff, J.K. 1994. Cardiac malpositions in patients with visceral heterotaxy. In The clinical recognition of congenital heart disease, 4th ed., pp. 40-50. Saunders, Philadelphia, PA.

Phoon, C.K. and C.A. Neill. 1994. Asplenia syndrome: Insight into embryology through an analysis of cardiac and extracardiac anomalies. Am. J. Cardiol. 73: 581-587.

Rossant, J. 1996. Mouse mutants and cardiac development: New molecular insights into cardiogenesis. Circ. Res. 78: $349-353$.

Schulte-Merker, S., J.C. Smith, and L. Dale. 1994. Effects of truncated activin and FGF receptors and of follistatin on the inducing activities of $\mathrm{BVgl}$ and activin: Does activin play a role in mesoderm induction? EMBO /. 13: 3533-3541.

Schumacher, A., C. Faust, and T. Magnuson. 1996. Positional cloning of a global regulator of anterior-posterior patterning in mice. Nature 383: 250-253.

Seo, J.-W., N.A. Brown, S.Y. Ho, and R.H. Anderson. 1992. Abnormal laterality and congenital cardiac anomalies: Relations of visceral and cardiac morphologies in the iv/iv mouse. Circulation 86: 642-650.

Simon, J. 1995. Locking in stable states of gene expression: Transcriptional control during Drosophila development. Curr. Opin. Cell Biol. 7: 376-385.

Stein, S., R. Fritsh, L. Lemaire, and M. Kessel. 1996. Checklist: Vertebrate homeobox genes. Mech. Dev. 55: 91-108.

Subramanian, V., B.I. Meyer, and P. Gruss. 1995. Disruption of the murine homeobox gene $\mathrm{Cdxl}$ affects axial skeletal identities by altering the mesodermal expression domain of Hox genes. Cell 83: 641-653.

Suemori, H., N. Takahashi, and S. Noguchi. 1995. Hoxc-9 mutant mice show anterior transformation of the vertebrae and malformation of the sternum and ribs. Mech. Dev. 51: 265 273.

ten Dijke, P., H. Yamashita, H. Ichijo, P. Franzén, M. Laiho, K. Miyazono, and C.-H. Heldin. 1994. Characterization of type I receptors for transforming growth factor- $\beta$ and activin. Science 264: 101-104.

van der Lugt, N.M.T., J. Domen, K. Linders, M. van Roon, E. Robanus-Maandag, H. te Riele, M. van der Valk, J. Deschamps, M. Sofroniew, M. van Lohuizen, and A. Berns. 1994. Posterior transformation, neurological abnormalities, and severe hematopoietic defects in mice with a targeted deletion of the bmi-1 proto-oncogene. Genes \& Dev. 8: 757769.

Van Praagh, S., F. Santini, and S.P. Sanders. 1992. Cardiac malpositions with special emphasis on visceral heterotaxy (Asplenia and Polysplenia syndromes). In Nadas' pediatric cardiology (ed. D.C. Fyler), pp. 589-608. Hanley \& Belfus, Philadelphia, PA.

Wilkinson, D.G. 1992. In situ hybridization: A practical approach. Oxford University Press, London, UK.

Wrana, J.L., L. Attisano, R. Wieser, F. Ventura, and J. Massagué. 1994. Mechanism of activation of the TGF- $\beta$ receptor. $\mathrm{Na}$ ture 370: 341-347.

Yamashita, H., P. ten Dijke, D. Huylebroeck, T.K. Sampath, M. Andries, J.C. Smith, C.H. Heldin, and K. Miyazono. 1995. Osteogenic protein-1 binds to activin type II receptors and induces certain activin-like effects. I. Cell Biol. 130: 217226.

Yasuda, Y., M. Okamoto, H. Konishi, T. Matsuo, T. Kihara, and T. Tanimura. 1986. Developmental anomalies induced by all-trans retinoic acid in fetal mice: I. Macroscopic findings. Teratology 34: 37-49.

Yasui, H., M. Nakazawa, M. Morishima, S. Miyagawa-Tomita, and K. Momma. 1995. Morphological observations on the pathologenetic process of transposition of the great arteries induced by retinoic acid in mice. Circulation 91: 2478-2486.

Yokoyama, T., N.G. Copeland, N.A. Jenkins, C.A. Montgomery, F.F.B. Elder, and P.A. Overbeek. 1993. Reversal of leftright asymmetry: A situs inversus mutation. Science 260: 679-682.

Yu, B.D., J.L. Hess, S.E. Horning, G.A.J. Brown, and S.J. Korsmeyer. 1995. Altered Hox expression and segmental identity in Mll-mutant mice. Nature 378: 505-508.

Zhang, W., R.R. Behringer, and E.N. Olson. 1995. Inactiviation of the mitogenic bHLH gene MRF4 results in up-regulation of myogenin and rib anormalies. Genes \& Dev. 9: 1388-1399. 


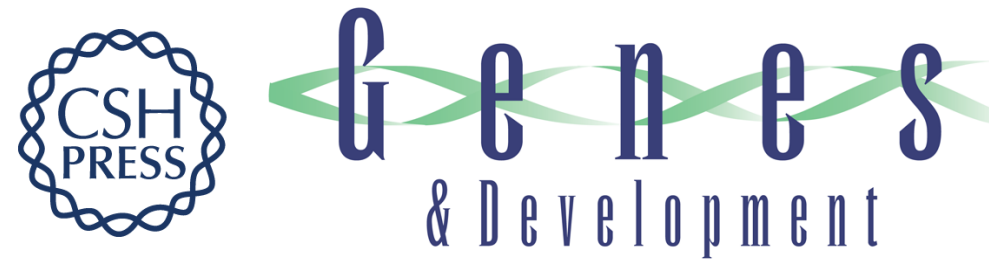

\section{The signaling pathway mediated by the type IIB activin receptor controls axial patterning and lateral asymmetry in the mouse.}

S P Oh and E Li

Genes Dev. 1997, 11:

Access the most recent version at doi:10.1101/gad.11.14.1812

References This article cites 80 articles, 29 of which can be accessed free at:

http://genesdev.cshlp.org/content/11/14/1812.full.html\#ref-list-1

License

Email Alerting

Receive free email alerts when new articles cite this article - sign up in the box at the top

Service right corner of the article or click here.

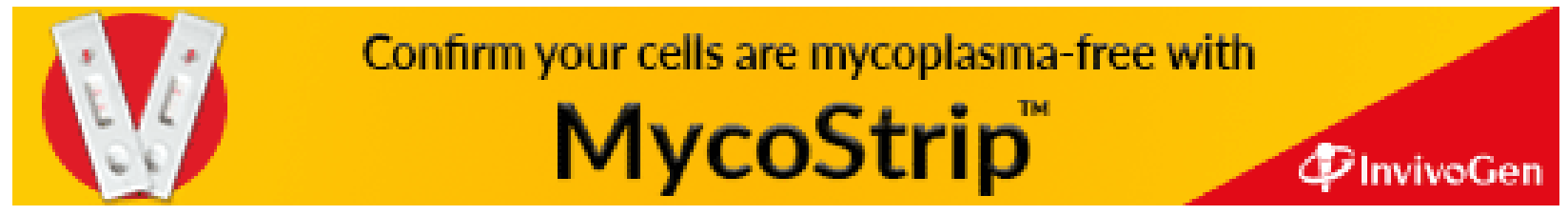

